\title{
Loss of Sensitivity in an Analog Neural Circuit
}

\author{
Bart G. Borghuis, ${ }^{1}$ Peter Sterling, ${ }^{2}$ and Robert G. Smith ${ }^{2}$ \\ ${ }^{1}$ Howard Hughes Medical Institute, Janelia Farm Research Campus, Ashburn, Virginia 20147, and ${ }^{2}$ Department of Neuroscience, University of \\ Pennsylvania, Philadelphia, Pennsylvania 19104-6085
}

\begin{abstract}
A low-contrast spot that activates just one ganglion cell in the retina is detected in the spike train of the cell with about the same sensitivity as it is detected behaviorally. This is consistent with Barlow's proposal that the ganglion cell and later stages of spiking neurons transfer information essentially without loss. Yet, when losses of sensitivity by all preneural factors are accounted for, predicted sensitivity near threshold is considerably greater than behavioral sensitivity, implying that somewhere in the brain information is lost. We hypothesized that the losses occur mainly in the retina, where graded signals are processed by analog circuits that transfer information at high rates and low metabolic cost. To test this, we constructed a model that included all preneural losses for an in vitro mammalian retina, and evaluated the model to predict sensitivity at the cone output. Recording graded responses postsynaptic to the cones (from the type A horizontal cell) and comparing to predicted preneural sensitivity, we found substantial loss of sensitivity (4.2-fold) across the first visual synapse. Recording spike responses from brisk-transient ganglion cells stimulated with the same spot, we found a similar loss (3.5-fold) across the second synapse. The total retinal loss approximated the known overall loss, supporting the hypothesis that from stimulus to perception, most loss near threshold is retinal.
\end{abstract}

\section{Introduction}

The human brain, occupying only $1.3 \mathrm{~L}$ and drawing just $12 \mathrm{~W}$, is a marvel of spatial and energetic efficiency (Blinkov and Glezer, 1968; Sarpeshkar, 1998). But how efficiently does it execute one of its primary duties, the sequential transfer of information from one stage to the next? Because neural signal transmission relies on chemical synapses, which are intrinsically noisy, one might expect each transfer to lose some sensitivity. Yet a small visual stimulus that near contrast threshold activates just one ganglion cell in retina (Borghuis et al., 2008) is detected in the spike train of the cell with about the same sensitivity as it is detected behaviorally (Watson et al., 1983; Dhingra et al., 2003; Borghuis et al., 2008). This single-cell sensitivity led Barlow (1972) to suggest that a spiking neuron could transfer information essentially without loss.

However, a different approach indicates that somewhere in the brain information is lost (Banks et al., 1987, 1991; Geisler, 1989). These studies started with a stimulus whose defined information content sets an upper bound to detectability. Then, a model was used to account for all known "preneural" factors that affect detectability, including light scatter, spectral sensitivity, and estimated photoisomerization efficiency. After accounting for these losses, the evoked response was presented to an "ideal observer" that used a maximum likelihood rule to "detect" it in a simulated two-alternative, forced-choice (2AFC) task. This ob-

Received Oct. 21, 2008; revised Jan. 19, 2009; accepted Jan. 20, 2009.

This work was supported by National Institutes of Health Grants EY000828, EY008124, and EY016607. We thank Jian Li for electron microscopy and Martin Lankheet for instruction on horizontal cell recordings. We thank Narender Dhingra for his generous assistance early in the project and for contributing a measurement of the optical density of the retina. We are grateful to Jon Demb and Martin Lankheet for comments on this manuscript.

Correspondence should be addressed to Bart $G$. Borghuis at the above address. E-mail: borghuisb@janelia.hhmi.org.

D0I:10.1523/JNEUROSCI.5071-08.2009

Copyright $\odot 2009$ Society for Neuroscience $\quad$ 0270-6474/09/293045-14\$15.00/0 server is termed "ideal" because, introducing no additional noise, its performance gives the upper bound for detection, before any neural circuit is engaged. In daylight, for stimuli near contrast threshold that approximate a ganglion cell receptive field, the ideal observer is more sensitive than a real (human) observer by 5- to 10-fold (Banks et al., 1987, 1991; Crowell et al., 1988; Savage and Banks, 1992).

Because sensitivity loss after the first spiking stage is apparently minor, whereas the overall loss is apparently substantial, we hypothesized that the main sensitivity loss occurs in the retina, where graded signals are processed by analog circuits. Such circuits transmit signals with high sensitivity and low metabolic cost (de Ruyter van Steveninck and Laughlin, 1996; Laughlin et al., 1998; Sterling and Freed, 2007) but tend to accumulate noise that inevitably degrades sensitivity (Sarpeshkar, 1998; Dhingra and Smith, 2004).

Our purpose was to test this hypothesis: we first built a model for a mammalian retina (guinea pig) that could be studied in vitro, and then used it with an ideal observer to calculate how much sensitivity is lost across the first two analog signaling stages. Recording from horizontal cells, we found substantial loss across the first visual synapse, and recording from brisk-transient ganglion cells, we found similar loss across the second synapse, for an overall $\sim 12$-fold loss. The corresponding ganglion cells in primate have smaller dendritic fields and fewer synapses, but because circuits and release mechanisms are conserved, the fractional losses should be similar. Thus, loss of sensitivity in the retina seems to explain the overall loss measured psychophysically.

\section{Materials and Methods}

Experimental design. Our basic plan was as follows: (1) to build a model of the photoreceptor array including all preneural factors, and then, following previous studies, to measure its threshold for detecting the brief 
appearance of a small spot against a uniform background (Banks et al., 1987, 1991; Geisler, 1989; Savage and Banks, 1992; Kiorpes et al., 2003); (2) to record from the type A horizontal cell, whose sole synaptic input derives from cones, and measure its threshold for detecting the same stimulus; the ratio of sensitivities, preneural/horizontal cell would give the sensitivity loss (if any) across the first synapse; (3) to extend the model to include the first "neural factor" (i.e., whatever loss occurred at the first synapse); and (4) to record from the brisk-transient ganglion cell, whose sole excitatory input is a homogeneous array of fast bipolar cells (Freed and Sterling, 1988), and determine its threshold to the same stimulus. The ratio of sensitivities, preneural plus neural/ganglion cell, would give the sensitivity loss across the second synapse.

Model for preneural factors. Because the model was to be compared with recordings from the retina in vitro, it omitted the optics of the eye but included photon loss caused by scatter and reflection from the surface of the perfusion medium. This was measured radiometrically (International Light) with a detector placed under the recording chamber. For photons reaching the photoreceptors, absorption by the photopigment depends on (1) the density of rod and cone photoreceptors, measured from immunostained retinal whole mounts (see Fig. 1A,B); (2) length and diameter of photoreceptor outer segments, measured from electron micrographs (see Fig. 1C); (3) known photopigment density, spectral sensitivity, and absorption efficiency plus estimated efficiency of photoisomerization (see Fig. 1, references). The model receptor array comprised a $500-\mu \mathrm{m}$-diameter patch of retina, corresponding to the receptive field center of a brisk-transient ganglion cell. It contained 4000 cones and 24,000 rods.

Rods were included as well as cones because guinea pig rods, like those of other mammals, form gap junctions with cones (Raviola and Gilula, 1975; Nelson, 1977; Smith et al., 1986; Schneeweis and Schnapf, 1995; Hornstein et al., 2005). Consequently, although a cone bipolar and a type A horizontal cell receive chemical synapses exclusively from cones, a substantial portion of the photovoltage in the cone terminal can come from rods (Schneeweis and Schnapf, 1995). Importantly, at the photopic intensities used here, guinea pig rods do not saturate but, depending on light level, actually account for $50-80 \%$ of the response in type A horizontal cells (Yin et al., 2006). This can be explained by rod adaptation at photopic intensities, which has been demonstrated in several cone-sparse species including rabbit and cat (Tamura et al., 1989; Nakatani et al., 1991). Therefore, at each light level, we accounted for the specific rod contribution to the cone signal reported by Yin et al. (2006), measured in the same preparation. Because the rod to rod bipolar synapse is saturated at the light levels used here (Berntson et al., 2004), we can safely ignore the rod bipolar to AII pathway and assume that all contrast information in a ganglion cell comes through the direct cone bipolar pathway.

To determine detection threshold at the level of the photoreceptor outer segments, we first computed the photoisomerization rate in a single rod and cone. Then, using a maximum-likelihood rule (Duda et al., 2001), we computed rod and cone detection threshold as the spot contrast that gave $1 \mathrm{SD}$ change in the mean response, conforming to the standard psychophysical criterion for a single trial, two-alternative, forced-choice experiment (Green and Swets, 1966). Using the square root law, which states that the precision of the sample mean improves with the square root of the sample size, we then computed from the single rod and cone threshold $\left(D_{\text {rod }} ; D_{\text {cone }}\right)$ the detection threshold for all rods and cones stimulated by the spot $\left(n_{\text {rods }} ; n_{\text {cones }}\right)$ as follows:

$$
D_{\text {rods }}=D_{\text {rod }} \cdot \sqrt{n_{\text {rods }}} \text { and } D_{\text {cones }}=D_{\text {cone }} \cdot \sqrt{n_{\text {cones }}} \text {. }
$$

Then, using the known fraction $a$ of rod signal in the cone signal, which is light dependent and decreases monotonically from almost $100 \%$ in dim light to $\sim 50 \%$ in bright light (Yin et al., 2006), we computed detection threshold for the combined rod and cone signal as follows:

$$
D_{\text {rods }+ \text { cones }}=\sqrt{a \cdot D_{\text {rods }}^{2}+(1-a) \cdot D_{\text {cones }}^{2}} \text {. }
$$

Completeness of the model. Our model included all relevant preneural factors listed in the pioneering work by Geisler (1989), assembled from studies spanning more than two decades of research (see Fig. $1 D$, references). We omitted one factor that conceivably applied to our wholemount preparation: the orientation of the photoreceptor outer segments.
In the intact eye, the cone inner segments are colinear with the light path. A photon entering the inner segment is funneled forward, as in a fiber optic, into the stacks of photopigment in the outer segment. In our preparation, the retina was radially incised and flattened onto adherent filter paper. Although no creases or folds were visible, this abnormal configuration may alter the photoreceptor orientation. If misalignment were substantial, photon capture would be reduced because of the StilesCrawford effect (Stiles and Crawford, 1933). However, we think this effect is minor, for two reasons.

First, we reconstructed the photoreceptor array in a whole-mount preparation from a $z$-stack of differential interference contrast (DIC) images. We found that, in the recorded area, the photoreceptor orientation and the direction of the incident light differed $<20^{\circ}$. Given the refractive index of 1.4 of a cone inner segment (Snyder and Pask, 1973), most photons entering the cone at this incident angle would not exit the cone but instead would be reflected or "guided" into the photopigment of the outer segment. Second, the Stiles-Crawford effect is known to disappear under scotopic conditions and has therefore been ascribed to the tapered, conical shape of the cone outer segments. Indeed, the StilesCrawford effect in humans is stronger in the periphery, where cone outer segments are more conical than in the fovea (Westheimer, 1967). Electron micrographs show that the outer segments of guinea pig cones in the visual streak are in fact not conical, but rod-shaped (see Fig. 1C). Therefore, if the effect depends on the shape of the outer segment, then in guinea pig cones it should be negligible. For these two reasons, we considered that any reduction in photon capture efficiency caused by cone misalignment could be safely ignored. Moreover, even if the Stiles-Crawford effect would reduce photon capture by up to $20 \%$, the effect on preneural contrast detection threshold would be minor $(<0.05$-fold change).

The second factor that was omitted from the ideal model was dark noise. One might include dark noise in an ideal model because it occurs at a similar locus to rhodopsin isomerization $\left(R^{*}\right)$, but strictly speaking it is a "neural" factor. In the original preneural model, dark noise was implicitly assumed to be negligible (Banks et al., 1987, 1991) or arbitrarily small $\left(20-80 R^{*}\right.$ cone $\left.{ }^{-1} \mathrm{~s}^{-1}\right)$ (Geisler, 1989). However, when cone dark noise was finally measured in the salamander L-cone $\left(\lambda_{\max }=\right.$ $620 \mathrm{~nm}$ ), it was found to be substantial $\left(\sim 600 R^{*} \mathrm{~s}^{-1}\right)$ (Rieke and Baylor, $2000)$. The guinea pig visual streak contains only M-cones, whose dark rate may be lower by $\sim 100$-fold because of increased stability of the photopigment (Ala-Laurila et al., 2004), counteracted by the higher working temperature, which increases photopigment instability. To allow comparison with the studies of Banks et al. and Geisler, we first assessed neural losses of contrast sensitivity in the absence of dark noise and later included it when we aimed to explain the measured loss (see Discussion). Rod dark noise was omitted throughout because even at the lowest light level in our experiments, the rod dark event rate was 1400fold smaller than the stimulus evoked $R^{*}\left(0.0063\right.$ against $\left.9.12 R^{*} \mathrm{~s}^{-1}\right)$ (Baylor et al., 1984).

Electrophysiology. An adult guinea pig (400-700 g) of either sex was anesthetized with ketamine $\left(40 \mathrm{mg} \cdot \mathrm{kg}^{-1}\right)$ plus xylazine $\left(5 \mathrm{mg} \cdot \mathrm{kg}^{-1}\right.$, i.m.), followed by pentobarbital $\left(50 \mathrm{mg} \cdot \mathrm{kg}^{-1}\right.$, i.p.). Then the eyes were removed and the animal was killed by intracardiac injection of pentobarbital $\left(20 \mathrm{mg} \cdot \mathrm{kg}^{-1}\right)$. Eyes were placed in oxygenated $\left(95 \% \mathrm{O}_{2}-5 \% \mathrm{CO}_{2}\right)$ Ames medium (Sigma-Aldrich) containing sodium bicarbonate (1.9 $\left.\mathrm{g} \cdot \mathrm{L}^{-1}\right)$ and glucose $\left(3.6 \mathrm{~g} \cdot \mathrm{L}^{-1}\right)$. The anterior one-half and vitreous humor were removed; the posterior one-half of each eye was radially incised and mounted on filter paper with ganglion cell layer up, preserving the attachment of the retina to pigment epithelium, choroid, and sclera. The preparation was then transferred to a recording chamber on an upright microscope and superfused at $4-6 \mathrm{ml} \cdot \min ^{-1}, \mathrm{pH} 7.3$ and $36^{\circ} \mathrm{C}$. All procedures conformed to National Institutes of Health and University of Pennsylvania guidelines.

Stimuli were computer-generated and displayed on a monochrome miniature CRT monitor (Lucivid; MicroBrightField; P43 phosphor with peak emission at $543 \mathrm{~nm}$ ), projected on the retina through the microscope optics [ $4 \times$; numerical aperture (NA), 1.3]. The stimulated area on the retina was $3.2 \times 2.4 \mathrm{~mm}$. Mean background intensity was varied over $3.7 \log$ units via a computer-controlled, radial neutral density filter. 
Mean intensities ranged from low mesopic to high photopic $\left(5.0 \times 10^{1}\right.$ to $2.5 \times 10^{5}$ photons $\mu \mathrm{m}^{-2} \mathrm{~s}^{-1}$; equivalent to $7.2-3.6 \times 10^{4} R^{*}$ cone ${ }^{-1}$ $\mathrm{s}^{-1}$ and $9.5-4.7 \times 10^{4} \mathrm{R}^{*} \operatorname{rod}^{-1} \mathrm{~s}^{-1}$ ) and radiant flux of the stimulus was measured regularly. Stable recordings of up to $1.5 \mathrm{~h}$ were needed to measure the detection threshold of a cell to a briefly flashed $(100 \mathrm{~ms})$ spot over a range of background intensities, contrasts $(0+0.5-20 \%)$ and extents (50-2000 $\mu \mathrm{m}$ diameter), with 200 repeats for each stimulus. Zero-contrast "null" trials were included to assess the background activity from which the stimulus-evoked activity was discriminated. To minimize adaptation artifacts, background intensity was incremented monotonically, and at each background intensity, stimulus contrasts were presented in a random interleaved order. Each flash was followed by 900 ms of background level illumination.

Horizontal cell recordings. A horizontal cell was impaled with a glass electrode (typical impedance, 70-200 M $\Omega$ ) backfilled with Neurobiotin (Vector Laboratories) and a fluorescent dye (Alexa Fluor 488 or 568; Invitrogen) in KAc $(1.5 \mathrm{M})$. The electrode was advanced through the retina from the ganglion cell side and horizontal cell penetration was detected from an approximately linear response to full-field flicker (1.0 $\mathrm{Hz} ; 20 \%$ contrast). Noise level in these recordings was low: the SD of the recorded membrane potential under steady, low-photopic illumination was $216 \pm 91 \mu \mathrm{V}(n=35)$. Because this approached the noise level for the electrode in the bath $(147 \pm 24 \mu \mathrm{V} ; n=21)$, we calculated the effect of electrode noise on the measurement of contrast threshold. In the frequency range relevant for the ideal observer $(0-12.5 \mathrm{~Hz}$, because of $40 \mathrm{~ms}$ bins), the ratio of intrabath to intracell noise amplitude (SD) was 2.3. Because the electrode and horizontal cell noise variances sum, the horizontal cell noise level was $\sqrt{ }\left(2.3^{2}-1\right)=2.07$-fold higher than that of the electrode. For the most sensitive cells, this underestimated actual sensitivity, but by no more than $10 \%$, and this slight underestimate was ignored in the analysis.

After recording, a cell was dye injected with current pulses through the electrode $( \pm 1 \mathrm{nA}, 1 \mathrm{~Hz} ; 1 \mathrm{~min})$. Tissue was then fixed (20 min; $4 \%$ paraformaldehyde), Neurobiotin was cross-reacted with fluorophoreconjugated streptavidin (Invitrogen), and cell type, type A or type B (Peichl and González-Soriano, 1994), was determined from the dendritic morphology obtained with a confocal laser-scanning microscope (Olympus BX; $40 \times$ objective; NA, 1.3). We report results for type A horizontal cells only.

Ganglion cell recordings. Viewed under infrared illumination with Hoffman optics and a CCD camera (Rolera-XR; QImaging), a brisktransient cell (ON or OFF) was selected for recording based on soma size (15-20 $\mu \mathrm{m}$ ), soma morphology, and transient light response (Borghuis et al., 2008). Recordings were obtained with glass electrodes (8-12 M $\Omega$ ) via loose seals. Cell type was confirmed by (1) transient response to a light increment (ON cells) or decrement (OFF cells); (2) peaks at 3-4 ms in the autocorrelogram; and (3) a biphasic temporal response characteristic, computed from the spike-triggered average of the cells response to a spatial binary white noise stimulus (Chichilnisky, 2001).

To measure contrast sensitivity, we flashed a $500-\mu \mathrm{m}$-diameter spot for $100 \mathrm{~ms}$, centered on the receptive field of the cell. This spot size matched the ganglion cell receptive field center diameter in bright light. Receptive field diameter increased slightly with decreasing intensity (by $<15 \%$ ); therefore, the spot never fell on the inhibitory surround.

The Weber contrast, as follows:

$$
C=\left(I_{s}-I_{b}\right) / I_{b}
$$

$\left(I_{s}=\right.$ spot intensity; $I_{b}=$ background intensity) was varied between 0 and $20 \%$, and comprised an intensity increment (bright spot) for ON cells and a decrement (dark spot) for OFF cells. Recordings were analyzed only when the responsiveness of a cell was stable for 200 trials. After recording, the cell was penetrated with a sharp electrode, filled with dye, and imaged by confocal microscopy to confirm type morphologically, using the same procedure as described for horizontal cells.

Contrast detection. Contrast detection threshold in a horizontal cell and ganglion cell was computed with an objective and widely applied method for signal detection (Geisler et al., 1991; Duda et al., 2001; Dhingra et al., 2003; Dhingra and Smith, 2004; Chichilnisky and Rieke,
2005). This method uses probability distribution functions obtained from computed or recorded responses. It applies a maximum-likelihood rule to decide whether (in our case) a spot was presented or not, based on the separation of the mean and variance of the response distribution. Hence the method may be applied to a Poisson rate, membrane voltage, or spike response, and detection performance is measured in the same units, and can be compared directly between response types. The discrimination procedure made minimal untested assumptions about how contrast stimuli are represented in the retina and was applied previously to compare rod and ganglion cell sensitivity (Chichilnisky and Rieke, 2005). Responses were accumulated into temporal bins, typically either 12 bins (to capture the pattern of the evoked response) or 1 bin (e.g., the total number of spikes). When multiple bins were used, the decision was based on reducing the response to one dimension. The response was reduced to a single value by multiplying by an optimal discriminant template (Duda et al., 2001).

We tested several discrimination templates that contained bin values equal to (1) the difference between the mean responses to the pair of stimuli (optimal when noise is invariant), (2) the difference between means divided by the variance (optimal when noise varies across time bins), and (3) the Fisher linear discriminant (multiplication by the inverse covariance matrix, optimal when noise changes and may be correlated). In agreement with the evaluations of various discriminant methods by Chichilnisky and Rieke (2005), the differences in performance were minor and the third (Fisher) template method was used for the data presented in Results. The template method was nearly optimal because the noise distributions were approximately normal and equivariant with small contrast increments (Duda et al., 2001).

Templates for the electrophysiological data consisted of multiple time bins with one free parameter, the bin width. Membrane voltage (horizontal cell) or spike rates (ganglion cell) of each $500 \mathrm{~ms}$ trial were averaged into 12, $40 \mathrm{~ms}$ bins (the last $20 \mathrm{~ms}$ of each trial was not used). This bin width was found to be optimal for horizontal cell responses and spike responses to the $100 \mathrm{~ms}$ stimulus, in agreement with Dhingra et al. (2003, 2004). Changes in the responses of the cells caused by light adaptation did not significantly alter the optimal bin width. Each response bin was multiplied by the corresponding template bin, and the resulting bin products were summed. This represents a dimensional reduction by a vector projecting in $n$-space, where $n=$ number of bins, and gives the best discrimination given the measured response distributions.

At each background intensity, we used one-half of the 200 trials recorded for each stimulus contrast to build the response probability distribution function of a cell. We then used the remaining trials as tests to measure contrast discrimination performance at each background intensity with a single interval, two-alternative forced-choice paradigm, in which the task was to discriminate flash trials (nonzero contrast) from no-flash "null" trials (zero contrast) (Green and Swets, 1966; Dhingra et al., 2003; Dhingra and Smith, 2004). For each trial from the test set, the probability value for each stimulus was looked up, and the stimulus that gave the highest probability was selected. The correct choices were tallied, and threshold was computed as the contrast that produced a $68 \%$ correct level of performance [equal to signal/noise ratio (SNR) of 1 for singleinterval 2AFC tasks]. A jackknife or "leave-one-out" method, in which templates were computed from all but one of the recorded responses and tested with the one left out, gave results identical with the half-half method used here.

\section{Results}

\section{Sensitivity loss from preneural factors}

We evaluated sequentially the various sources of sensitivity loss across the retina, starting with a briefly presented spot of light. How sensitively this spot can be detected depends directly on the number of photons delivered to the eye. At the level of the photoreceptor outer segments, the detection threshold follows from the distribution of absorbed photons as the SD divided by the mean, which for a Poisson process simplifies to 1 over the square root of the mean. Thus, the detection threshold at the first neural stage, in the rod and cone photopigment, is set by the photoi- 


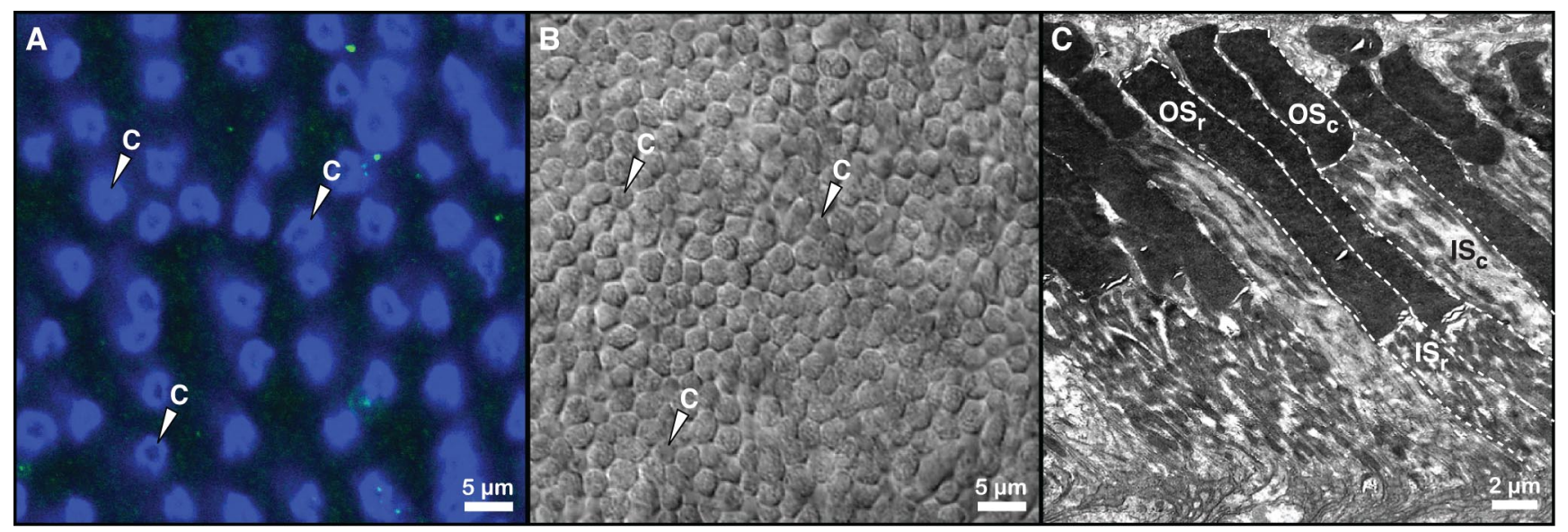

D

\section{Table of preneural factors}

\begin{tabular}{|c|c|c|c|}
\hline & cone & rod & \\
\hline scatter and reflection & 0.91 & 0.91 & \\
\hline retinal transmission & 0.88 & 0.88 & \\
\hline outer segment diameter & $2.0 \pm 0.13$ & $1.8 \pm 0.10$ & $\mu \mathrm{m}$ \\
\hline outer segment length & $8.1 \pm 0.9$ & $14 \pm 1.3$ & $\mu \mathrm{m}$ \\
\hline distribution density & 20,000 & 120,000 & $\mathrm{~mm}^{-2}$ \\
\hline specific optical density ${ }^{1}$ & 0.008 & 0.017 & $\mu m^{-1}$ \\
\hline spectral efficiency ${ }^{1,2}$ & 0.93 & 0.40 & \\
\hline isomerization efficiency $y^{3,4}$ & 0.66 & 0.66 & \\
\hline
\end{tabular}

${ }^{1}$ Parry and Bowmaker, 2002; ' Yin et al., 2006; ${ }^{3}$ Dartnall, 1968; ${ }^{4}$ Knowles, 1982

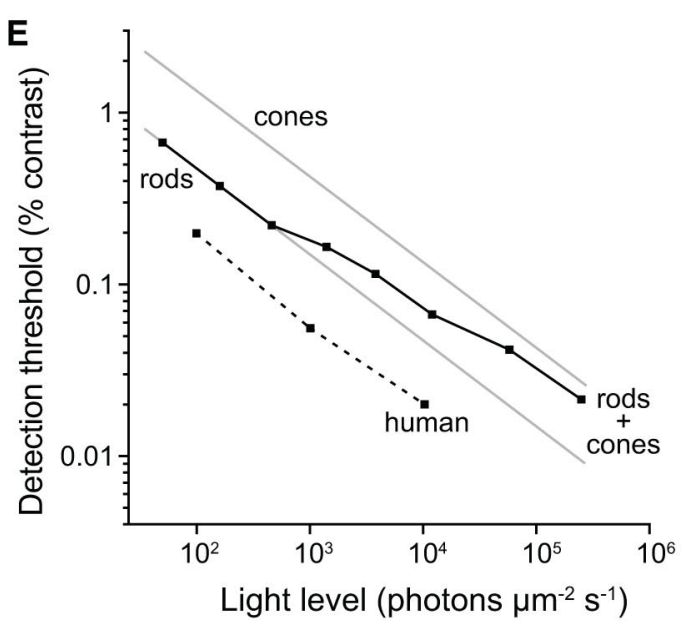

Figure 1. In guinea pig visual streak, the probability of photon capture is 12 -fold greater for rods than for cones. $\boldsymbol{A}$, Tangential section through cone array at the inner segment level (confocal). Peanut agglutinin stains the cones (c) blue. Cone distribution was calculated from a sixfold larger area. $\boldsymbol{B}$, Tangential section $\sim 10 \mu \mathrm{m}$ below the section shown in $\boldsymbol{A}$ (DIC). Each hexagon is a photoreceptor axon in cross section; " $c$ " marks cones indicated in $A$. Rods outnumbered cones by 6:1. C, Vertical section through the photoreceptors (electron micrograph). Rod (r) and cone outer segments had similar diameters, but rod outer segments were nearly twofold longer. IS, Inner segment; 0 S, outer segment. $\boldsymbol{D}$, Preneural factors used in the model. Most values represent our primary measurements, and the rest are widely accepted values from previous studies. Values represent data for middle wavelength-sensitive cones, which comprise $92-95 \%$ of the cones in the guinea pig visual streak (Röhlich et al., 1994). E, Contrast detection thresholds computed from the preneural model. Stimulus was a 500- $\mu \mathrm{m}$-diameter spot presented for $100 \mathrm{~ms}$ on a range of backgrounds. Thresholds for rod and cone arrays (gray curves) are parallel and separated by a factor of 3.5 , corresponding to the square root of their difference in photon catch. The black curve shows preneural detection with relative rod and cone sensitivities based on that of Yin et al. (2006). The dotted curve shows preneural sensitivity for human fovea [adapted from Geisler (1989)]. Because the stimulus was seven cycles of a sine wave grating that stimulated many ganglion cells, the absolute thresholds (separation on the vertical axis) cannot be compared, but the guinea pig and human models give the same slope, indicating dominance of photon fluctuation.

somerization rate. The first step in our analysis was to obtain this quantity from the product of stimulus photon flux, duration, photoreceptor area, and quantum efficiency.

To determine the photon flux at the level of the photopigment, we traced the losses of photons from stimulus source to the photoreceptors. The main loss in our experimental setup was reflection and scatter of light from the surface of the perfusion medium. We measured this by placing a radiometer under the glass slide base of the recording chamber, comparing photon flux with and without medium. For an intensity at the CRT of $1.20 \times$ $10^{4}$ photons $\mu \mathrm{m}^{-2} \mathrm{~s}^{-1}$ (which we will use as the example light level in the calculations that follow), the transmitted intensity at the level of the superfused retina was $1.12 \times 10^{4}$ photons $\mu \mathrm{m}^{-2}$ $\mathrm{s}^{-1}$, indicating a $9.3 \%$ loss of photons. Nonphotopigment absorption and scatter by the thin $(80 \mu \mathrm{m}$ from ganglion cell layer to the photoreceptor outer segments, measured from electron micrographs) (Fig. $1 C$ ) and nearly transparent retina was $12 \%$, measured from the light transmitted by a retina after bleaching, with the sclera and pigment epithelium removed (N. K. Dhingra, unpublished data). For each stimulus intensity $I_{\text {stim }}$, photon flux at the level of the photoreceptors $I_{\mathrm{rec}}$ was as follows:

$$
I_{\text {rec }}=I_{\text {stim }} \cdot(1-\gamma)\left(1-\mathrm{OD}_{\mathrm{ret}}\right) \text {, }
$$

where $\gamma$ is the total reflection off the superfusion medium surface and $\mathrm{OD}_{\text {ret }}$ is the optical density of the retina after bleaching of the photopigment. For the example light level, $I_{\text {rec }}$ was $9.6 \times 10^{4}$ photons $\mu \mathrm{m}^{-2} \mathrm{~s}^{-1}$.

Next, we calculated the quantum efficiency of the outer retina, which tells for a given number of photons entering the eye, how many photoisomerizations and subsequent transduction cascade reactions are initiated per unit time. First, we calculated how much photopigment was available for photon capture based on the photoreceptor distribution density and spatial dimensions. We measured the distribution densities of rods and cones in the visual streak, $0.8 \mathrm{~mm}$ above the horizontal meridian. At this locus, an optical section was taken tangentially through the layer of cone synaptic terminals that had been stained with peanut agglu- 
tinin. The section occupied $5000 \mu \mathrm{m}^{2}$ and contained 101 cones (Fig. 1A). A deeper section through the axons showed 692 photoreceptors (cones plus rods) (Fig. $1 B$ ). Thus the cone-to-rod ratio in the visual streak was 6 , and the respective densities were 20,000 cones $\mathrm{mm}^{-2}$ and 120,000 rods $\mathrm{mm}^{-2}$. These light microscope measurements agreed with our measurements from electron micrographs (Fig. 1C) and with previous reports by Peichl and González-Soriano (1994) (21,700 cones/mm²; 182,000 rods/ $\left.\mathrm{mm}^{2}\right)$, Röhlich et al. (1994) (17,900 cones $\left./ \mathrm{mm}^{2}\right)$, and Yin et al. (2006) $\left(20,000\right.$ cones $\left./ \mathrm{mm}^{2}\right)$.

Measured from electron micrographs, the cone outer segment diameter was $2.0 \pm 0.13 \mu \mathrm{m}$ and length was $8.1 \pm 0.9 \mu \mathrm{m}$; rod outer segment diameter was $1.8 \pm 0.1 \mu \mathrm{m}$ and length was $14 \pm$ 1.3. Because the cone inner segment may function as a wave guide, Geisler (1989) took 80\% of the cone inner segment diameter as the effective cone aperture. The inner segment diameter in guinea pig cones was $2.5 \pm 0.23 \mu \mathrm{m}$ and taking $80 \%$ of this would in fact give approximately the same collecting area as the outer segment diameter. Because the wave guide effect is arguably small and has not been demonstrated in the guinea pig visual streak, our computations used the outer segment diameter.

Next, we calculated for the photons that arrive at the photoreceptor outer segments, how many are absorbed in the photopigment. In the visual streak, $94 \%$ of the cones are middle wavelength sensitive ("green"). Taking into account this and the spatial dimensions of the rod and cone, spectral sensitivity (Röhlich et al., 1994; Yin et al., 2006), and the measured spectral content of our stimulus (see Materials and Methods), we calculated the number of absorbed photons $P$ for a single rod and cone as follows:

$$
P_{\text {rod,cone }}=I_{\text {rec }} \cdot A \cdot \beta \cdot\left(1-10^{-l O D_{\text {spec }}}\right),
$$

where $I_{\text {rec }}$ is the number of photons incident at the outer segment, $A$ is the outer segment cross-sectional area $\pi r^{2}$, with $r$ the outer segment diameter, $\beta$ is the spectral efficiency, $l$ is the outer segment length, and $\mathrm{OD}_{\text {spec }}$ is the specific optical density of the photopigment at the stimulus light wavelength $(543 \mathrm{~nm})$. All values used for the rod and cone calculations are assembled in a table in Figure $1 D$. Finally, absorbed photons isomerize the photopigment with an estimated isomerization efficiency of 0.66 (Dartnall, 1968; Knowles, 1982), so that the number of photoisomerizations follows from the number of absorbed photons as follows:

$$
R_{\text {rod,cone }}^{\star}=0.66 \cdot P \text {. }
$$

Dividing $R^{*}$ by the number of photons incident on the photoreceptor (stimulus intensity multiplied by outer segment crosssectional area), we calculated for a single rod a quantum efficiency of $9.1 \%$, which agrees with previous estimates (11-33\%) (Hecht et al., 1942; Barlow, 1962), and for a single cone a quantum efficiency of $4.7 \%$. Averaged over all rods and cones under the spot, quantum efficiency was $8.5 \%$.

\section{Contrast detection threshold after all preneural losses}

Using the factors enumerated above, we computed the contrast detection threshold for a $500 \mu \mathrm{m}$ spot with a standard 2AFC method for signal detection (see Materials and Methods). Spot size was chosen to match the receptive field size of the most sensitive cell at the retinal output stage, the brisk-transient ganglion cell (Dhingra et al., 2003; Xu et al., 2005), a functional type that is also found in rodent, cat, and primate retina. Stimulus duration was brief, $100 \mathrm{~ms}$, approximating the integration time of retinal neurons. Given the photoisomerization rate at a mean background of $1.2 \times 10^{4}$ photons $\mu \mathrm{m}^{-2} \mathrm{~s}^{-1}$ (cone, $1.8 \times 10^{3} R^{*}$ $\mathrm{s}^{-1}$; rod, $2.2 \times 10^{3} \mathrm{R}^{*} \mathrm{~s}^{-1}$ ), we computed that the detection threshold for a single cone was $7.6 \%$, and for a single rod, $6.6 \%$ contrast. Photon arrival in adjacent photoreceptors is statistically independent and Poisson distributed. Therefore, detection threshold is set by the SD of the total rate of photoisomerizations (i.e., the square root of the mean quantal rate). From the computed detection thresholds of a single rod and cone, it follows that the detection threshold for a flashed spot, which stimulated 4000 cones and 24,000 rods, at this particular intensity was $0.067 \%$ contrast (Fig. 1E).

If cone sensitivity were based on stimulus SNR alone, then sensitivity would improve as the square root of the photon flux. However, noise sources within the cone influence cone sensitivity, as do rod signals, which are transmitted to the cone through gap junctions (Nelson, 1977; Smith et al., 1986; Wu and Yang, 1988; Schneeweis and Schnapf, 1995). Consequently, the relationship between detection threshold and light intensity is more complex than a simple square root improvement (Fig. 1E, squares vs gray lines). At scotopic (starlight) through low mesopic (twilight) backgrounds, threshold is determined by sensitivity of the rod array, which has 12 -fold more photopigment because of a higher cell distribution density and longer outer segments (Fig. 1C). At higher intensities, as the rod contribution to the photovoltage of the cone terminal declines (Yin et al., 2006), thresholds increasingly reflect the cone curve (Fig. 1E). Over $3.7 \log _{10}$ units of intensity $\left(5.0 \times 10^{1}\right.$ to $2.5 \times 10^{5}$ photons $\left.\mu \mathrm{m}^{-2} \mathrm{~s}^{-1}\right)$, the preneural detection threshold improves 32 -fold, from 0.67 to $0.02 \%$ contrast (Fig. $1 E$ ).

\section{Transformations of the photosignal}

Next, we considered the first set of neural factors. The photocurrent in the photoreceptor outer segment is converted via diverse voltage-gated channels in the inner segment to a photovoltage that modulates voltage-sensitive calcium channels in the presynaptic terminal. The resulting calcium current modulates quantal release of glutamate that binds postsynaptic receptors to modulate, in graded manner, a postsynaptic voltage (Heidelberger et al., 2005; Sterling and Matthews, 2005). Sensitivity might be lost at any of these stages, but the first stage technically feasible to measure was postsynaptic, by intracellular recording from a horizontal cell. In principle, the same measurement could be obtained from cone bipolar cells, but these are smaller, harder to record stably, and of diverse types that differ in bandwidth.

Probing with intracellular microelectrodes reliably led to penetration of the type A horizontal cell, which could often be held stably for more than an hour. The bandwidth of the horizontal cell was comparable with that of the cone and fastest bipolar cell types (DeVries et al., 2006), implying that the losses that we measured were not caused by temporal filtering (Burkhardt et al., 2007). The horizontal cell and bipolar cell processes receive input from the same ribbon synapses, so their levels of synaptic noise should be identical. Thus, we assumed that the horizontal cell responses were representative of the excitatory signal that was transmitted through bipolar cells to ganglion cells, because both horizontal cells and bipolar cells are presumed to sample the same synaptic quanta released by cone ribbons.

To compare postsynaptic sensitivity measured in a horizontal cell with contrast sensitivity in the cones required that we determine what fraction of the cone output is sampled by the horizontal cell. This fraction is defined by the proportion of the presynaptic active zones of the stimulated cones sampled by the 

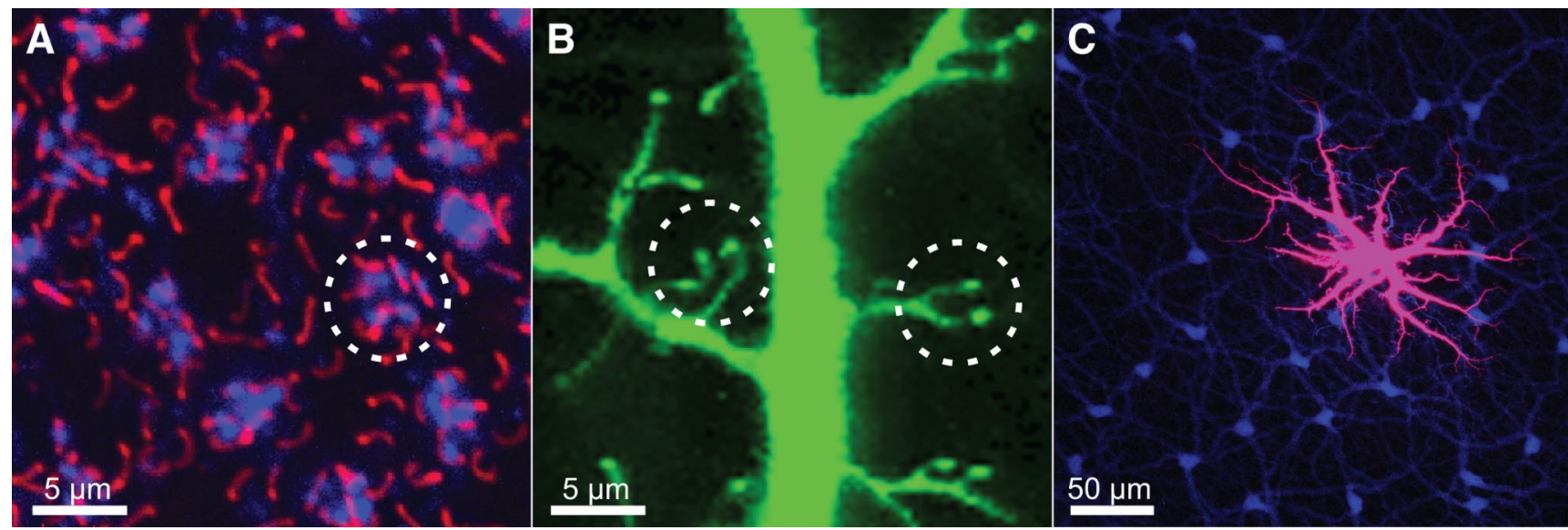

Figure 2. The horizontal cell syncytium samples from all cone synaptic ribbons. $\boldsymbol{A}$, Tangential section immunostained for ribbons (red, kinesin) and cone terminals (blue, peanut agglutinin). The cone synaptic terminal (dashed circle) contains 12 ribbons. $\boldsymbol{B}$, Detail of a dye-filled type A horizontal cell dendritic arbor showing clustered dendritic processes that sample from two to three ribbons in each cone terminal (dotted circles). $\boldsymbol{C}$, Tangential view of the type A horizontal cell syncytium demonstrating extensive gap junction coupling. The central cell (magenta) was injected with a mixture of fluorescent dye Alexa Fluor 568, which remained within the cell, and Neurobiotin, which traversed the gap junctions and spread to all coupled cells (blue).

horizontal cell. Thus, to validate our method, we enumerated the cone synaptic ribbons (which mark active zones) and also the invaginating horizontal cell dendritic processes. To determine the number of synaptic ribbons in a cone terminal, a fixed retina was immunostained for kinesin, using the methods described by Xu et al. (2008).

Each cone terminal contained $12.1 \pm 0.7$ ribbons (Fig. $2 A$ ). From intracellular dye injections, we observed that the spines from a horizontal cell process cluster in groups of two to three beneath each cone (Fig. $2 \mathrm{~B}$ ), in agreement with previous reports (Peichl and González-Soriano, 1994). We then determined the coverage factor for the type A horizontal cell. Neurobiotin injected into one cell filled its processes and because of its low molecular weight (formula weight, 322.8) spread via gap junctions to the neighbors (Fig. $2 C$ ). We measured an average dendritic field area of $2.0 \pm 0.3 \times 10^{-2} \mathrm{~mm}^{2}$, which lies within the range reported by Peichl and González-Soriano (1994), and a density of 276 cells $/ \mathrm{mm}^{2}$ (average of five confocal images obtained from four preparations). The product of area and density gave a coverage factor of 5.6.

Assuming that 5.6 horizontal cells contacted all cones cospatial with their arbors with two to three spines per cone, all 12 active zones in a cone terminal are accounted for, which means that the horizontal cells sample all presynaptic active zones of all cones. In cat retina, the number of ribbons per terminal and processes per horizontal cell cluster differ, but the same numerical match was observed there (Wässle et al., 1978a,b) and also in primate (Haverkamp et al., 2001). In short, the population of type A horizontal cells samples from all active zones in a cone synaptic terminal and because these cells are strongly coupled (Fig. 3C), the contrast signal measured in one horizontal cell represents the total contrast signal transmitted by all cones within the receptive field of the recorded cell. Because of the extensive electrical coupling of the horizontal cells, which averages out intrinsic noise, the noise measured in one horizontal cell represents the noise transmitted by the cones. Having quantified the anatomical circuit, we proceeded to measure contrast detection threshold in a type A horizontal cell.

\section{Contrast threshold of the type A horizontal cell}

To a low-contrast bright spot, the type A horizontal cell (Fig. $3 A$ ) responded with a hyperpolarization whose amplitude increased with contrast (Fig. 3B), and to a low-contrast dark spot, it responded with a depolarization of similar amplitude (Fig. 3B). At higher contrasts $(>20 \%)$, the response amplitude for a dark spot exceeded that for a bright spot by up to $50 \%$, demonstrating a difference in the response gain at high contrast (Fig. $3 B, C$ ). We ignored this difference because our measurements of threshold were made at contrasts $\ll 20 \%$.

Signal detection depends on the ratio of response amplitude to response variability. For the response of a cell to a spot, we measured both by recording responses to repeated stimulus presentations. From 200 responses to each spot contrast, we then used one-half to build response distributions and the other onehalf to test detection performance, by comparing each test response to the set of response distributions including the "null" response (no flash), and deciding whether a stimulus was presented using the maximum-likelihood rule (see Materials and Methods). This gave a neurometric function (Fig. 3D) that showed for each contrast the fraction of "correct" choices given the signal and noise amplitude of the cell. Following the convention for a single-interval, 2AFC procedure, detection threshold was defined as the contrast value that gave $68 \%$ correct discrimination between a zero (null stimulus) and nonzero contrast spot. Against a midphotopic background $\left(1.2 \times 10^{4}\right.$ photons $\mu \mathrm{m}^{-2}$ $\mathrm{s}^{-1}$ ), average detection threshold for a $500 \mu \mathrm{m}$ bright spot was $3.4 \%$ contrast (Fig. 3E). As expected from the similarity in $\mathrm{ON}$ and $\mathrm{OFF}$ response gain at low contrast, detection threshold for a dark spot was not significantly different (unpaired $t$ test, $p=0.07$ ).

\section{Horizontal cell coupling underestimated the cone signal}

The measured horizontal cell threshold was 48 -fold higher than the threshold calculated from the corresponding preneural model. But to compute the actual loss of contrast sensitivity across the cone synapse, we needed to correct for dissipation of the cone signal through the extensive electrical coupling of the horizontal cell (Fig. 2C). Responses to progressively larger spots showed that the receptive field of a horizontal cell exceeded the diameter of its dendritic field by up to 10 -fold (Fig. 4A), matching reports from rabbit (Dacheux and Raviola, 1982), and consistent with reported spatial frequency tuning functions for this cell type recorded from the same preparation (Zaghloul et al., 2007). Because the measured horizontal cell receptive field was substantially larger than the $500 \mu \mathrm{m}$ spot, the coupled network 

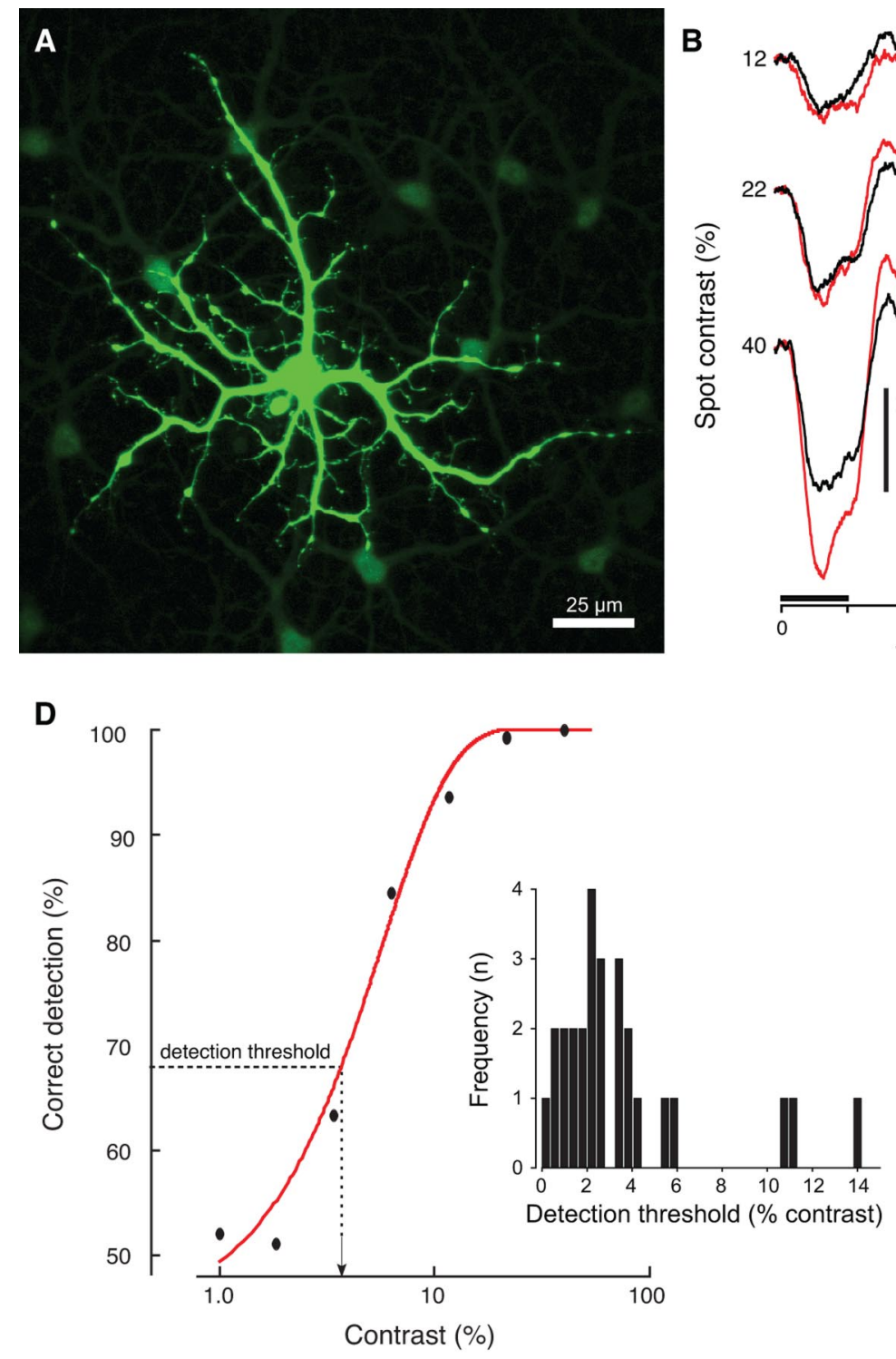
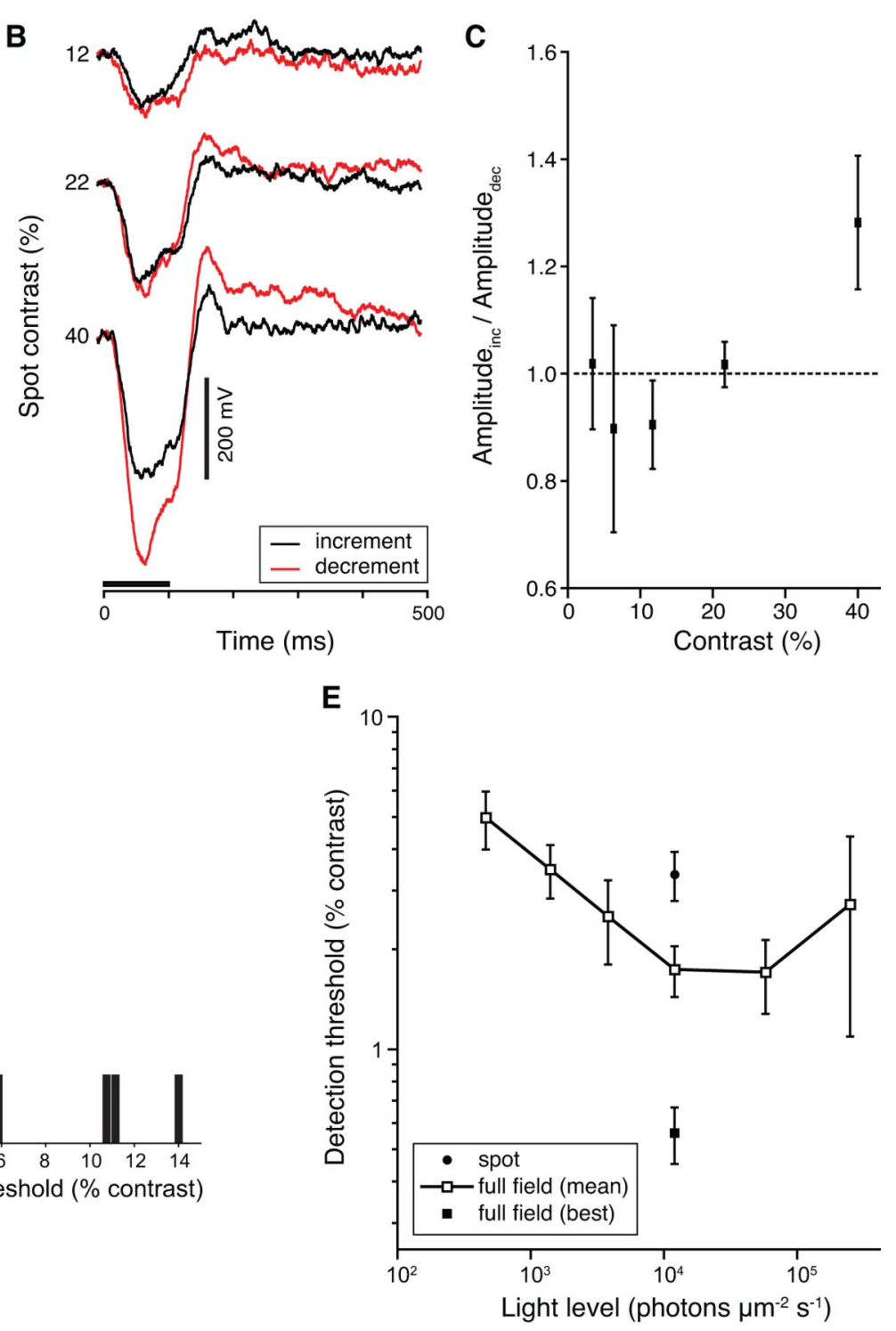

Figure 3. Measuring the horizontal cell detection threshold. A, Tangential view of a type A horizontal cell injected with Alexa Fluor 488 and Neurobiotin. B, Responses of this cell to a $100 \mathrm{~ms}, 500$ $\mu \mathrm{m}$ spot (each trace shows the average of 141 trials). At low contrast, responses to an increment (black) and decrement (red; inverted for comparison) are of opposite polarity but similar amplitude. This symmetry breaks at high contrast, at which the response is larger to a decrement. C, Averaged ratios of the peak response amplitudes for decrements and increments. Above $20 \%$ contrast, amplitudes for decrements are significantly larger than for increments $(p<0.01$; mean \pm SEM). $\boldsymbol{D}$, Neurometric function constructed from 200 responses to a flashed spot (same data as in $\boldsymbol{B}$ ). An ideal observer detects the flashed spot based on the recorded horizontal cell response and improves with increasing contrast. Threshold ( $68 \%$ correct) for this cell was $3.6 \%$ contrast. The inset shows the distribution of contrast detection thresholds for all cells at the optimal light intensity $\left(1.2 \times 10^{4}\right.$ photons $\left.\mu \mathrm{m}^{-2} \mathrm{~s}^{-1}\right)$. $E$, Detection threshold for a spot $(3.4 \% ; n=5)$ was higher than for a full-field stimulus, demonstrating that the horizontal cell receptive field is significantly larger then its dendritic field. Average detection threshold for a full-field stimulus fell with increasing background intensity, leveling off and then rising with cone saturation $(n=16)$. Detection threshold for the most sensitive recordings was $0.56 \%$ contrast $(n=4)$. Detection thresholds for increment and decrements were not significantly different $(p>0.1)$.

averaged the contrast signal of the cones so that the response recorded in the horizontal cell at the center of the spot underrepresented the contrast signal transmitted by the cones. In addition, the recorded horizontal cell collected the noise from all cones in the receptive field, both stimulated and not stimulated. These two factors necessarily reduced the measured sensitivity.

To null the effect of electrical coupling, we repeated the contrast measurement with a full-field light flash $(2.4 \times 3.6 \mathrm{~mm}$ on the retina) that stimulated all cones in the receptive field of the recorded horizontal cell. Because now all horizontal cells were equally stimulated, this configuration minimized lateral current flow within the network. Importantly, it also rendered the threshold measurements insensitive to changes in horizontal cell recep- tive field size that might have occurred with a change in mean light level, which was varied in these experiments.

As expected, detection threshold for a full-field flash was lower than for a spot. From mesopic to midphotopic intensities, contrast threshold measured in the horizontal cell fell monotonically; but at the highest intensities $\left(>10^{5}\right.$ photons $\left.\mu \mathrm{m}^{-2} \mathrm{~s}^{-1}\right)$, detection threshold increased (Fig. 3E). At the optimal light level of $1.2 \times 10^{4}$ photons $\mu \mathrm{m}^{-2} \mathrm{~s}^{-1}$ (the intensity that gave the best detection), average detection threshold was $1.74 \pm 0.30 \%$ contrast $(n=16)$. Across the recorded population, detection threshold ranged from 0.39 to $3.4 \%$ contrast, and from a dataset of 16 , the four most sensitive thresholds ranged from 0.39 to $0.84 \%$ contrast (average, $0.56 \pm 0.11 \%$ contrast). 

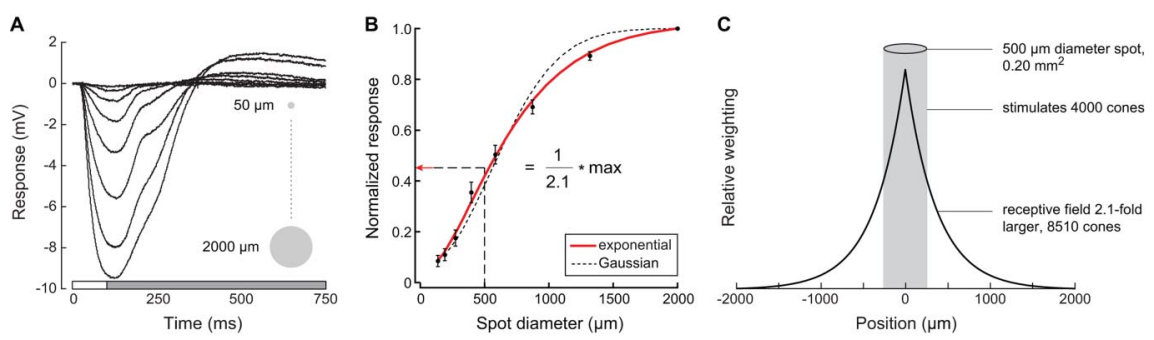

Figure 4. Correcting for horizontal cell coupling. $A$, Responses to spots of increasing size show spatial summation up to $2000 \mu \mathrm{m}$; thus, the receptive field exceeds the dendritic field diameter by $\sim 10$-fold. Receptive fields of type A horizontal cells in the guinea pig visual streak were fivefold larger than $\mathrm{H} 1$ horizontal cells in primate retina at $60^{\circ}$ eccentricity (Packer and Dacey, 2002). Cell-to-cell variability in guinea pig, however, was much smaller ( $<10 \%$ ) and matched that of primate horizontal cells at $25^{\circ}$ eccentricity (Packer and Dacey, 2002). B, To compute how receptive field size affects the measured contrast signal, we first computed the response to a $500 \mu \mathrm{m}$ spot. This was on average 2.1 -fold smaller than the response of the cell to a full-field flash of the same contrast and duration ( $n=5$; mean \pm SEM). C, Knowing the cone density and horizontal cell spatial weighting function (derived from the spot size measurements), we calculated that the ratio of stimulated cones to total cone input to is 4000/8510. This ratio was used to compute the SNR of the contrast signal of a single cone from the SNR measured in the horizontal cell (for details, see Materials and Methods and Results).

We found no correlation between dendritic field size and detection threshold. This was expected because the extensive electrical coupling should average out most differences in sensitivity because of individual size variations. The higher contrast thresholds we attribute to cell damage caused by the intracellular electrode and to variability in the recording location in the dendrite, which ranged from large primary dendrites to fine peripheral dendrites. Fluorescence microscopy of dye-filled cells confirmed that recordings from the dendritic field center gave larger response amplitudes and better SNR than cells recorded peripherally (data not shown). Both types of artifact would give a skewed distribution of contrast detection thresholds with a short tail on the low end and a long shallow tail on the high end, which was consistent with the data (Fig. 3D, inset) (skewness, 2.8). Consequently, the examples of poorest sensitivity were attributed to cell damage and a reduced signal quality and were omitted from the analysis; the most sensitive recordings were taken to best represent the true sensitivity at the level of the horizontal cells.

\section{Sensitivity loss across the first synapse}

Sensitivity loss from one stage to the next is proportional to the decrease in signal/noise ratio. In the previous section, signal/ noise ratio at the level of the cone input was computed with the ideal model. Next, we determined signal/noise ratio at the level of the cone output, using the intracellular responses of a horizontal cell and its detection threshold to full-field and spot stimuli. From the known cone density and the receptive field size and spatial weighting function of the horizontal cell, we calculated back to the output signal/noise ratio of a single cone. This was then compared with the signal/noise ratio of the ideal model to measure the loss.

First, we corrected for electrical coupling by postulating that the horizontal cell obtained its SNR by integrating the signals from all stimulated cones $\left(N_{s}\right)$ and the noise from all cones in its receptive field $\left(N_{n}\right)$. Signals from the cones sum linearly in the horizontal cell. But through electrical coupling, the signal of a cone dissipates across the receptive field. Signal in the horizontal cell therefore increases proportionally to the number of stimulated cones divided by the number of cones in the receptive field. Noise in the horizontal cell decreases proportional to the square root of the number of cones in the receptive field (square root law). Because the horizontal cell weights cones toward the receptive field edge more weakly, the effective cone noise depends on the shape of the spatial receptive field (Hemilä et al., 1998).

We measured the receptive field profile of the horizontal cell from the spot size versus response function measured in the mid- photopic $\left(1.2 \times 10^{4}\right.$ photons $\left.\mu \mathrm{m}^{-2} \mathrm{~s}^{-1}\right)$ (Fig. $\left.4 B\right)$. This was fit well by a radial Bessel-type exponential function with a length constant of $182 \mu \mathrm{m}$ (root mean square error, 1.9\%) (Fig. 4A, B). The effective number of cones in the measured horizontal cell receptive field for this weighting function was $0.25 \cdot N_{n}$ (Hemilä et al., 1998). SNR in the horizontal cell then follows from the cone signal and noise functions as follows:

$$
\mathrm{SNR}_{\mathrm{HA}}=\frac{\text { Signal }_{\text {cone }} \cdot \frac{N_{s}}{N_{n}}}{\text { Noise }_{\text {cone }} / \sqrt{0.25 \cdot N_{n}}},
$$

which simplifies to the following:

$$
\mathrm{SNR}_{\mathrm{HA}}=\mathrm{SNR}_{\text {cone }} \cdot \delta \cdot \sqrt{0.25 \cdot N_{n}} \text {, where } \delta=\frac{N_{s}}{N_{n}} \text {. }
$$

Here, $\delta$ accounts for the dissipation of cone signal from stimulated to nonstimulated areas in the horizontal cell network (Hemilä et al., 1998), $N_{n}$ is the total number of cones in the receptive field of the horizontal cell (8510; computed from Fig. $4 \mathrm{~B}$ ) and $N_{s}$ the number of stimulated cones. For the spot stimulus, $N_{s}=4000$ and $\delta=0.47$; for the full field measurement, $N_{s}=$ 8510 and $\delta=1$. Thus, from the (more sensitive) full-field measurement, we calculated the horizontal cell/cone SNR ratio to be 46.1.

Because SNR is inversely proportional to the contrast detection threshold $D$,

$$
\mathrm{SNR}_{\mathrm{HA}} \propto \frac{1}{D_{\mathrm{HA}}},
$$

the postsynaptic signal of a single cone would give a detection threshold $D_{\text {cone }}$ that is 46 -fold higher than the detection threshold measured in the horizontal cell $(0.39 \%$ for a full-field flash against a background of $1.2 \times 10^{4}$ photons $\left.\mu \mathrm{m}^{-2} \mathrm{~s}^{-1}\right)$. This gives for a single cone a detection threshold of $18.0 \%$ contrast. The most sensitive detection threshold measured with the spot ( $1.1 \%$ contrast) gave a cone detection threshold of $22.7 \%$, close but slightly higher than the value calculated from the full-field measurement, which might reflect the smaller sample size of the spot measurements and greater sensitivity to variations in the receptive field size.

These calculations converted the detection threshold measured in a horizontal cell, which was biased by its electrical coupling and specific receptive field shape, into the expected detection threshold postsynaptic to a single cone. Assuming that the 


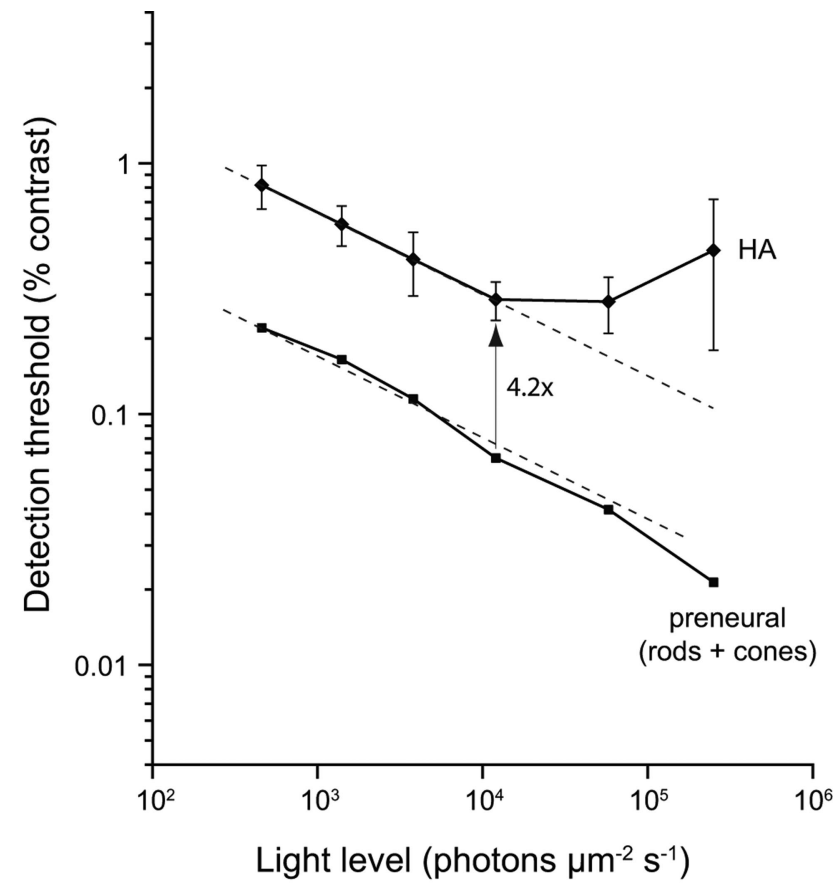

Figure 5. From mesopic to midphotopic intensities, contrast threshold of type A horizontal cell paralleled the preneural threshold but was higher by fourfold. The preneural detection curve shown here is reproduced from Figure $1 E$. It combines rod and cone sensitivities because the cone terminal receives substantial rod input before it contacts the horizontal cell. Horizontal cell detection threshold, corrected for gap-junction coupling (Fig. 5), was 0.81\% contrast at the lowest intensity and fell to $0.28 \%$ contrast in the midphotopic. Thus, between $10^{2}$ and $10^{4}$ photons $\mu \mathrm{m}^{-2} \mathrm{~s}^{-1}$, horizontal cell detection threshold (HA) closely paralleled the preneural curve (dashed reference lines are exactly parallel). Above $\sim 5 \times 10^{4}$ photons $\mu \mathrm{m}^{-2} \mathrm{~s}^{-1}$, horizontal cell detection threshold rose, probably because of photopigment bleaching in this in vitro preparation. That the observed loss of sensitivity did not reflect a pathological state in vitro was confirmed with control experiments, in which changing light levels from low to high and then back to low gave sensitivities identical with the initial measurements at the low light level. The sensitivity loss at high intensity recovered rapidly $(<1 \mathrm{~min})$ and recovery resembled adaptation to equivalent downward changes from lower intensities.

noise collected from the cones is uncorrelated, the detection threshold improves with the square root of the number of sampled cones:

$$
D=\frac{D_{\text {cone }}}{\sqrt{n}} .
$$

Therefore, it follows that an ideal detector that combined the postsynaptic signals from all 4000 cones stimulated by the spot would detect it at $0.28 \%$ contrast. For the same spot at the same light level, the detection threshold of the preneural model was $0.067 \%$. Thus, from phototransduction to the postsynaptic signal of the cones, the factorial sensitivity loss was as follows:

$$
\frac{D_{\text {postsynaptic }}}{D_{\text {preneural }}}=4.2 \text {-fold } \text {. }
$$

Comparing sensitivity from mesopic to midphotopic intensities, the falling limb of the threshold curve exactly paralleled the thresholds computed from the preneural model (Fig. 5). Because the horizontal cell samples from the cones, sensitivity measured in a horizontal cell should follow not the square root of the photon flux (Fig. 1E), but the cone sensitivity calculated with the preneural model. The latter deviates from proportionality to the log of the photon flux because of the light dependence of the rod contribution. That horizontal cell sensitivity indeed parallels cal- culated preneural sensitivity supports the model. It also implies that the loss of contrast sensitivity across this range of light adaptive states is constant. Which stages after phototransduction are mainly responsible for the considerable (4.2-fold) loss of contrast sensitivity will be addressed in Discussion. At high photopic intensities, the slope of rising limb of the curve departed sharply from the preneural curve, implying a decline in neural efficiency that can be explained by bleaching of the photopigment (Fig. 5, legend).

\section{Contrast threshold of the brisk-transient ganglion cell}

Next, we asked how much of the contrast sensitivity after the first synaptic stage remains after the second synaptic stage. To answer this, we recorded the extracellular spike responses of a ganglion cell of the brisk-transient class (both ON and OFF types) while presenting the $500 \mu \mathrm{m}$ spot, centered on and fully covering the dendritic field of the cell (Fig. 6A). The brisk-transient class was chosen from among about a dozen types because, like the type A horizontal cell, it (1) through the bipolar cells collects from all the cones cospatial with its dendritic field (Cohen and Sterling, 1990; Wässle et al., 2009) and (2) connects via a brisk-transient bipolar type with the highest bandwidth (Freed and Sterling, 1988; DeVries et al., 2006; Sterling and Freed, 2007). Thus, for the brief stimulus used here, it should retain the most information (Koch et al., 2006). Furthermore, the numbers of bipolar synapses onto this type are known, along with their vesicle release dynamics (Freed, 2000; Xu et al., 2008).

A brisk-transient ganglion $\mathrm{ON}$ cell responded to a light spot with a brief burst of spikes, and the same was observed for an OFF cell stimulated with a dark spot. Two factors modulated the ganglion cell spike response: background intensity and spot contrast. As background intensity increased, the response spike rate increased to peak in the midphotopic. Additional increases in background intensity gave a reduced response rate, both in $\mathrm{ON}$ and in OFF cells (Fig. $6 \mathrm{~B}$, columns). That the spike response of the cells was maximal at an intermediate light level was not specific to the spot stimulus: a control experiment showed the same result for the response to spatiotemporal white noise (Fig. 6C). At each background intensity, decreasing the spot contrast reduced the spike response (Fig. $6 B$, rows).

How sensitively could a spot be detected from these responses? For a spot of low contrast $(<3 \%)$, not every stimulus presentation evoked a spike. This impaired detection, as shown by the neurometric function (Fig. 6D). A change in mean light intensity shifted the neurometric function of the cell to a higher or lower contrast value mostly without a change in the slope (Fig. $6 D)$. For both $\mathrm{ON}$ and OFF cells, contrast detection improved with increasing light intensity up to the midphotopic $\left(\sim 1 \times 10^{4}\right.$ photons $\mu \mathrm{m}^{-2} \mathrm{~s}^{-1}$ ). It then declined, similar to the results for horizontal cells. At the optimal intensity, detection threshold was $1.37 \pm 0.44 \%$ contrast for OFF cells $(n=22)$ and $3.01 \pm 0.58 \%$ contrast for ON cells $(n=16)$. Detection threshold for the most sensitive cell was $0.56 \%$ (OFF) and $1.42 \%$ contrast (ON). Average and lowest thresholds for $\mathrm{ON}$ cells were higher by approximately twofold compared with OFF cells, but fell within the range reported by Dhingra et al. (2003).

In summary, ON cells were less sensitive than OFF cells but both types had the same dynamic response range and showed a similar shape and slope in their neurometric functions across light levels (data not shown). 

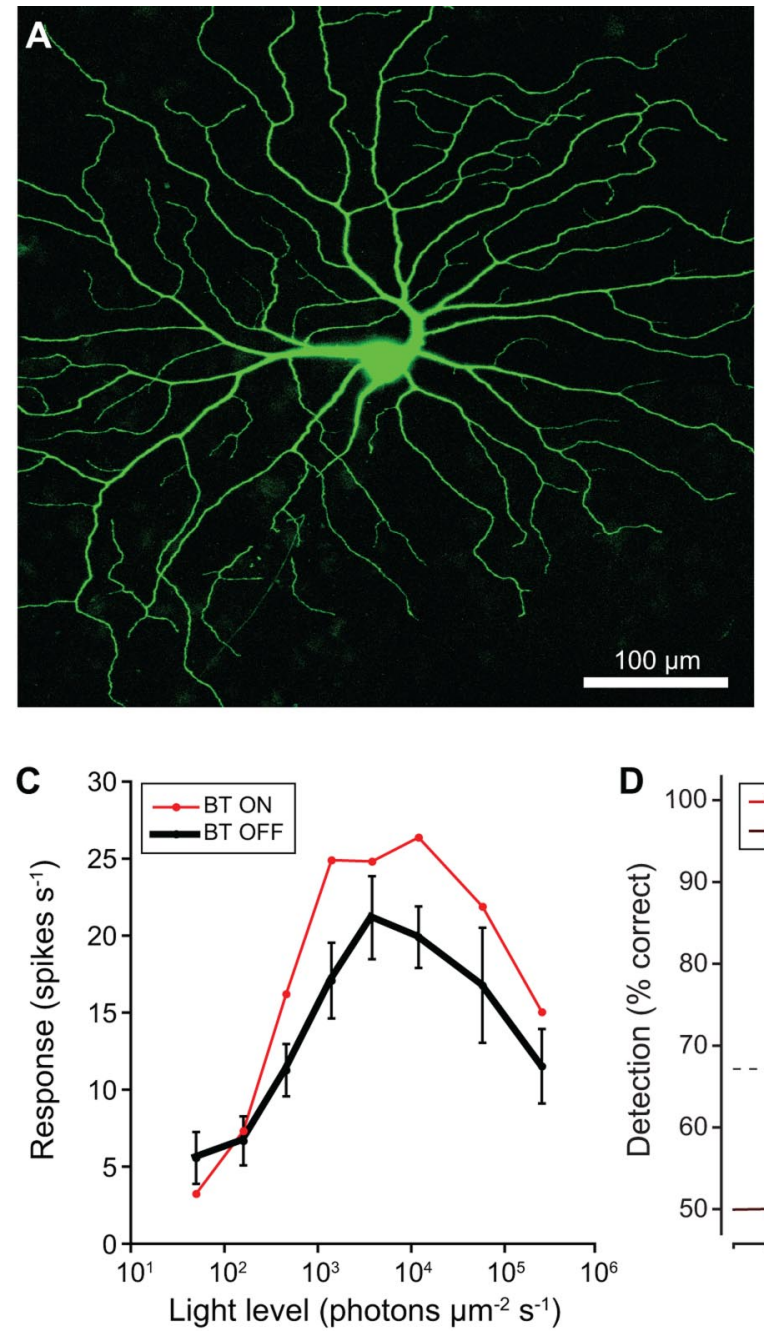

B

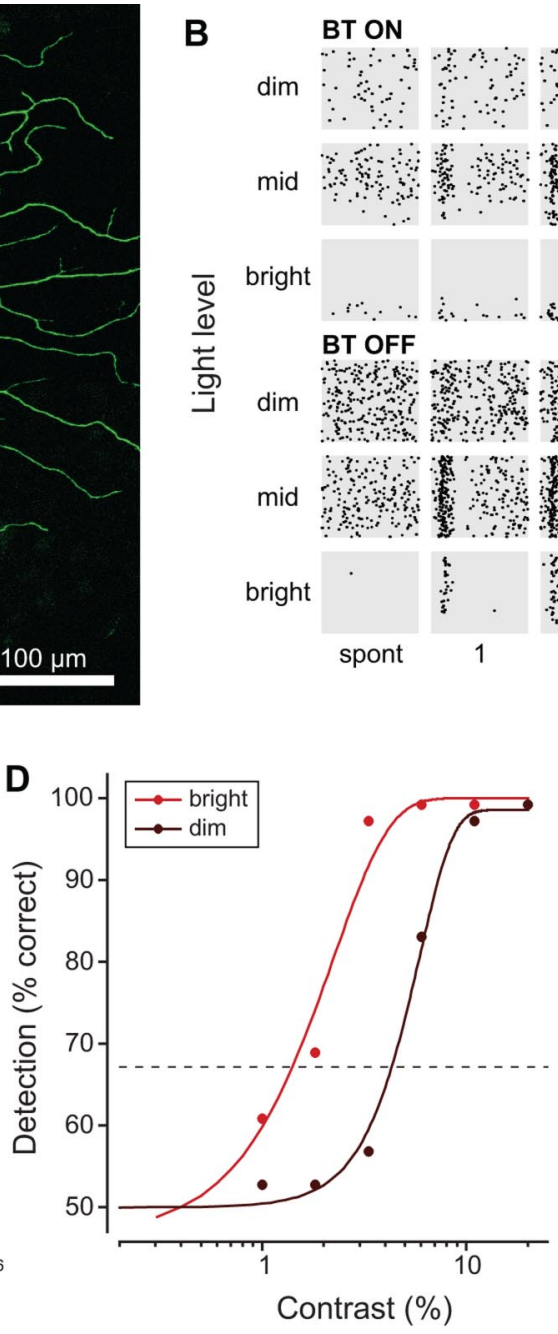

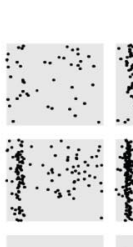

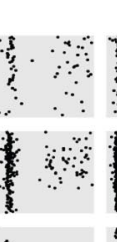

(a)
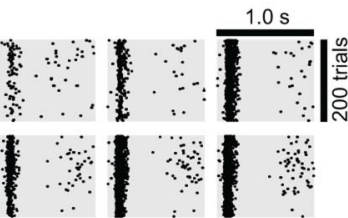

a $\therefore .$.

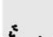

; $\cdots, \ldots$

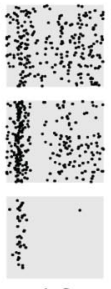

1.8

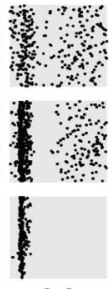

3.3

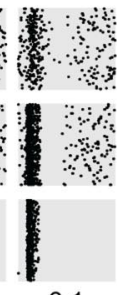

6.1

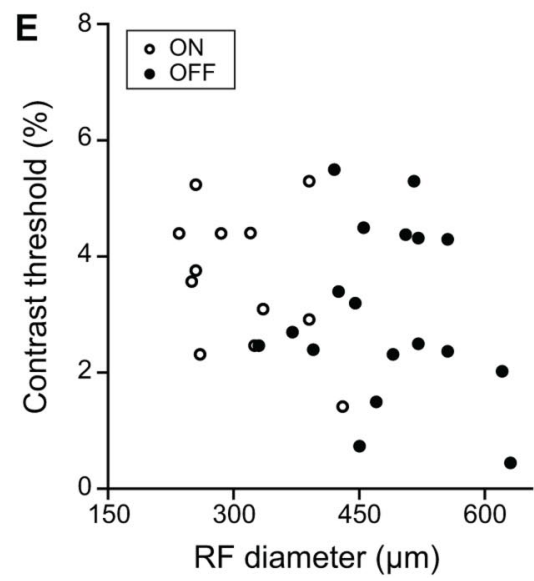

Figure 6. Detection threshold for the most sensitive ganglion cells was $<1 \%$ contrast. $\boldsymbol{A}$, Tangential view of an OFF brisk-transient ganglion cell. $\boldsymbol{B}$, Raster plots of spike responses: 0 N cell above; OFF cell below (morphology shown in $\boldsymbol{A}$ ). Stimulus was a spot ( $100 \mathrm{~ms}, 500 \mu \mathrm{m}$ diameter; light increment for $0 \mathrm{~N}$ cells, decrement for $0 \mathrm{FF}$ cells) centered on the receptive field of the cell. Each dot represents a spike; within a gray box, each horizontal row represents a trial. Contrast measurements were repeated at different mean light levels (rows: dim, $4.6 \times 10^{2}$; mid, $3.8 \times 10^{3} ;$ bright, $5.8 \times 10^{4}$ photons $\mu \mathrm{m}^{-2} \mathrm{~s}^{-1}$ ). C, Average firing rate for $\mathrm{ON}$ and OFF cell stimulated with spatiotemporal white noise (20\% contrast) at different mean intensities. $\boldsymbol{D}$, Neurometric curves for an OFF cell from data shown in B. Detection threshold falls from 4.4\% (dim) to 1.3\% contrast (bright). $\boldsymbol{E}$, Within a type (ON or OFF), contrast detection threshold at the optimal light intensity (typically $1.2 \times 10^{4}$ photons $\mu \mathrm{m}^{-2} \mathrm{~s}^{-1}$ ) was uncorrelated with receptive field size. Average $0 \mathrm{~N}$ receptive fields were smaller, and $0 \mathrm{~N}$ cells had slightly higher detection thresholds (see Results). However, detection thresholds for the most sensitive $0 \mathrm{~N}$ and $0 \mathrm{FF}$ cells were comparable.

\section{Sensitivity loss across the second synapse}

We compared the detection threshold measured in the ganglion cell to the thresholds at the preneural and first neural stage. To make a valid comparison required that we account for the fact that a ganglion cell dendritic field sums its inputs with a Gaussian weighting function (Xu et al. 2008). This effectively reduces the number of contributing cones by two-fold and thus reduces SNR by $\sqrt{ } 2$-fold (Hemilä et al., 1998). Because detection threshold is proportional to SNR, threshold measured in the ganglion cell underestimates contrast sensitivity after the second synaptic stage by the same factor.

The measured detection threshold for the $500 \mu \mathrm{m}$ spot $(1.37 \%)$ implies that because the ganglion cell effectively samples just $1 / \sqrt{ } 2$ of it, integrating the total contrast signal transmitted at the second synaptic stage would give a $\sqrt{ }$ 2-fold lower threshold, $0.97 \%$ contrast. Comparison with the detection threshold measured after the first synapse $(0.28 \%$ ) (see above) implies a 3.5 -fold loss in contrast sensitivity from the cone synapse (postsynaptically) to the ganglion cell. Calculated for the most sensitive gan- glion cells $(0.48 \% ; n=3)$, this inner-retinal loss was lower, 1.7-fold.

From mesopic to midphotopic intensities, contrast detection thresholds measured in a ganglion cell decreased, closely paralleling the preneural and horizontal cell thresholds. At high photopic intensities, detection threshold increased, diverging from the preneural threshold, but remaining parallel to the horizontal cell threshold. The increase in threshold at high light intensity can be explained by saturation in the signaling pathway (see Discussion), and because the curves for horizontal cells and ganglion cells are parallel also at the intensities at which saturation commences, this saturation most likely originates in the cones.

If light intensity does not affect signaling efficiency at the first and second synapse, then from dim to bright light, the ratio of contrast thresholds, ideal/horizontal cell and ideal/ganglion cell, should be constant. Indeed, we found that from $5 \times 10^{1}$ to $1 \times$ $10^{4}$ photons $\mu \mathrm{m}^{-2} \mathrm{~s}^{-1}$, this ratio for horizontal cells was mostly constant at $\sim 4$ (Fig. $7 B$ ). Additional increase in light intensity increased the ratio, reflecting the divergence of preneural and 

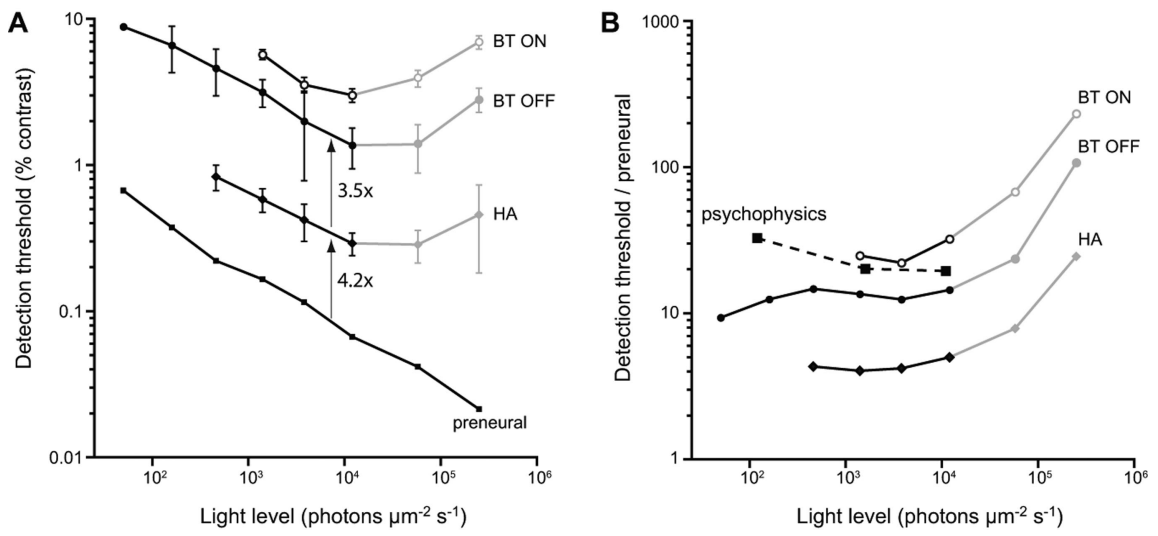

Figure 7. From mesopic to midphotopic intensities, ganglion cell contrast thresholds paralleled the preneural and horizontal cell thresholds. $\boldsymbol{A}$, Ganglion cell detection thresholds decline with light intensity, paralleling preneural threshold over $\sim 2.5 \mathrm{log}$ units. Then, at $10^{4}$ photons $\mu \mathrm{m}^{-2} \mathrm{~s}^{-1}$, the curve (gray) flattens, and above $5 \times 10^{4}$ photons $\mu \mathrm{m}^{-2} \mathrm{~s}^{-1}$, it rises, diverging from the preneural curve. Because the effect is the same for horizontal cells and ganglion cells, it must originate in the outer retina, probably from cone bleaching in this in vitro preparation. Across the intensity range, the OFF ganglion cell curve was 3-fold higher than the horizontal cell curve and 12 -fold higher than the preneural curve. $\boldsymbol{B}$, Relative signaling efficiency, computed as the ratio of measured sensitivity to preneural sensitivity, is approximately constant from the mesopic to midphotopic. The efficiency curve for human contrast detection (psychophysical threshold/preneural threshold) [from Banks et al. (1991), their Fig. 3] lies between the two ganglion cell curves. Neural curves rise (gray) at higher intensities, as would be expected from photoreceptor bleaching.

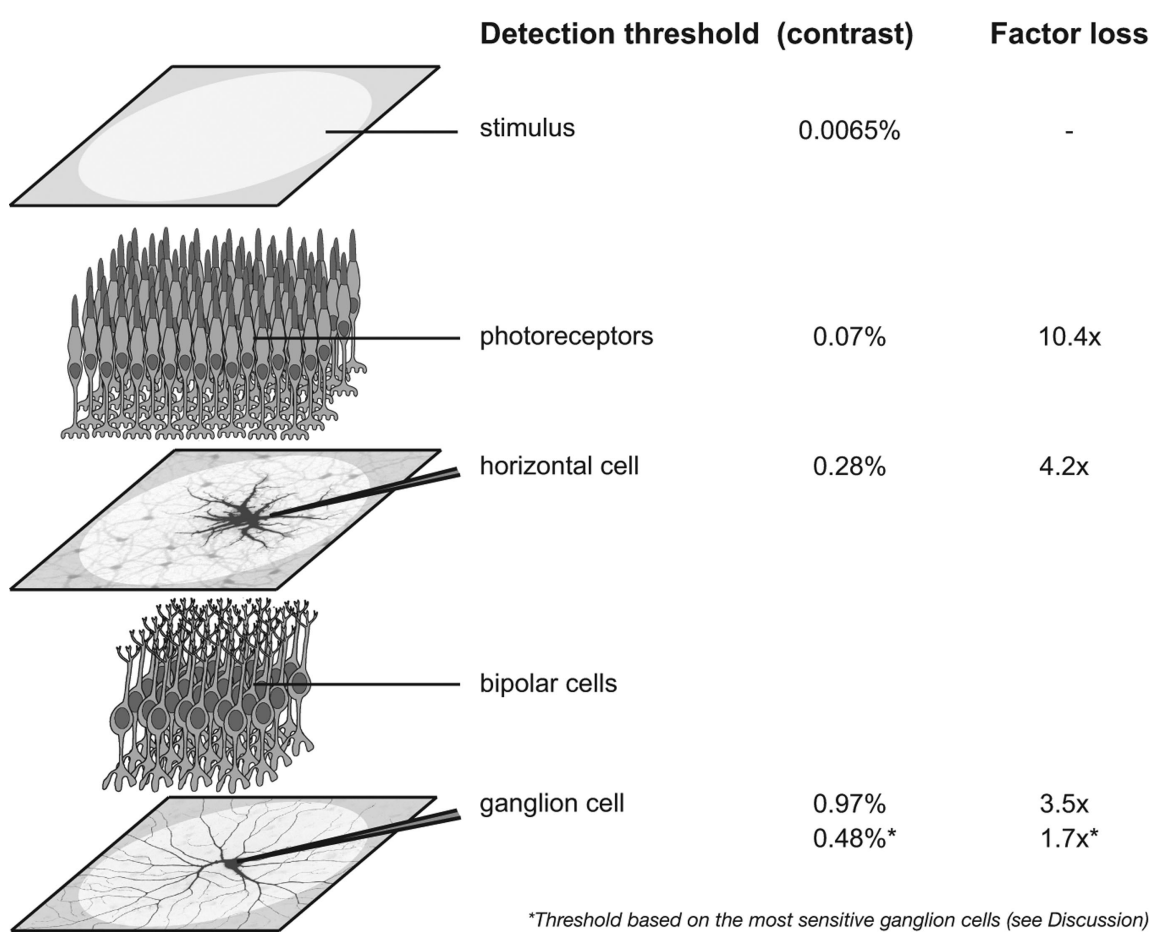

Figure 8. Overall loss of contrast information across the retina is $\sim 10$-fold. Based on the stimulus SNR, against a background of $1 \times 10^{4}$ photons $\mu \mathrm{m}^{-2} \mathrm{~s}^{-1}$, a spot can be detected at $0.007 \%$ contrast. But losses caused by preneural factors raise detection threshold in the photoreceptor by 10-fold, to $0.07 \%$ contrast. After the first synapse, detection threshold was $0.28 \%$ contrast, implying a 4.2-fold loss. After the second synapse and correction for the spatial weighting function of the ganglion cell, average detection threshold was $0.97 \%$, implying a 3.0-fold loss at the second synapse. These losses combined give a 12 -fold overall loss for a contrast signal transmitted across the retina. Threshold based on the most sensitive ganglion cells (see Discussion) was $0.48 \%$ contrast, which gives 1.5 -fold loss at the second signaling stage, and a 6.3-fold overall loss.

neural thresholds at high light levels (Fig. 7A). The ratio of contrast threshold, ideal/ganglion cell, was higher than for horizontal cells, 9-12, but had the same shape across light levels (Fig. 7B). These results demonstrate that, at the first and second visual synapse, the efficiency of contrast signaling is approximately con- stant and suggest that the decrease in very bright light originates presynaptically, in the cones.

\section{Discussion}

We asked how much sensitivity is lost across two synaptic stages of an analog neural circuit? To answer this, we compared contrast detection near threshold by a preneural model of a mammalian cone array to detection by a horizontal cell that senses the cone output, and then to detection by a ganglion cell that senses the bipolar output. Because the horizontal cells sample the same ribbon synapses as the bipolar cells that contact the ganglion cell, we expect, although have not proven, that the bipolar cells suffer the same losses. Both neuron types match the cone bandwidth. Loss was 4.2-fold from cone to horizontal cell and 3.5-fold from bipolar to ganglion cell (1.5-fold for the most sensitive ganglion cells). These fractional losses were constant across light intensities (mesopic to midphotopic) and rose in parallel at higher intensities with cone saturation. Overall loss was thus 6- to 12-fold (Fig. 8).

This degree of loss might seem surprising given that a weak flash (one to five absorbed photons) can be detected behaviorally (Hecht et al., 1942) and that a single photoisomerization can evoke one to three spikes in a ganglion cell (Barlow et al., 1971; Mastronarde, 1983). Yet the rod bipolar pathway mediating these responses in starlight is specialized to transmit binary single-photon signals over a limited range of backgrounds (Taylor and Smith, 2004) and therefore need not transmit graded signals in the same lossy manner as cone pathways.

\section{Accuracy of the preneural model}

The preneural model included all the factors used in preneural models of human vision (Banks et al., 1987; Geisler, 1989; Sekiguchi et al., 1993) with several factors evaluated specifically for guinea pig: retinal transmission, photoreceptor dimensions and distributions, spectral sensitivities, and relative rod and cone contributions. Were any single factor in error by a factor of 2 (which seems unlikely), the calculated loss would vary by $\sqrt{ } 2$-fold. Then the calculated loss across the first synapse, rather than being 4.2 , could be as low as 3 or as high as 5.7. This would not change our conclusions.

\section{Accuracy of the detection threshold measurements}

Measuring the contrast threshold of a horizontal cell required stable intracellular recordings for $20 \mathrm{~min}$ at each intensity. At the optimal intensity, measured thresholds varied by 10 -fold ( 0.39 to $>3 \%$ con- 
trast), probably because of cell damage. Assuming that the lowest thresholds represent the least damage, we used the four most sensitive recordings $(0.56 \%$ contrast $)$.

Detection thresholds for brisk-transient ganglion cells (1.4\%) were twofold lower than a previous report using the same method and preparation (Dhingra et al., 2003). This difference is explained by the different mean light intensities. The lowest thresholds here were measured at $12 \times 10^{3}$ photons $\mu \mathrm{m}^{-2} \mathrm{~s}^{-1}$. Using $7.9 \times 10^{3}$ photons $\mu \mathrm{m}^{-2} \mathrm{~s}^{-1}$, like Dhingra et al., we reproduced their result. Although our OFF cells had lower detection thresholds than ON cells ( 1.4 vs 3.0\% contrast), we consider this difference to be spurious, arising because most $\mathrm{ON}$ cells were recorded in later experiments on smaller animals. The ON centers were smaller than the OFF centers ( $392 \pm 98$ vs $504 \pm 92 \mu \mathrm{m})$, whereas typically, they are 1.5-fold larger (Chichilnisky and Kalmar, 2002; Borghuis et al., 2008; Manookin et al., 2008). Corrected for size, the ON cell detection threshold fell to $2.1 \%$, close to the average OFF cell threshold).

\section{Contrast is signaled with constant efficiency}

The detection curves for preneural, horizontal, and ganglion cells run parallel from mesopic to midphotopic backgrounds, implying that from cone to horizontal cell and bipolar to ganglion cell, contrast signaling efficiency is constant. This is consistent with psychophysical studies showing similar parallelism with preneural models (Banks et al., 1987). The horizontal cell to ganglion cell parallelism is independent of the preneural model and fits the finding that, in daylight, light adaptation occurs before the first synapse (Dunn et al., 2007). In dimmer light $\left(<10^{3}\right.$ photons $\left.\mu \mathrm{m}^{-2} \mathrm{~s}^{-1}\right)$, in which inner retinal mechanisms mediate light adaptation (Dunn et al., 2007), one expects horizontal cell and ganglion cell sensitivities to diverge.

\section{Causes of sensitivity loss}

One possible cause of sensitivity loss is dark noise in the cones (Rieke and Baylor, 2000). Calculations show that, in dim light, dark noise would decrease SNR by severalfold if the cones were not coupled to their surrounding rods. However, because of the coupling, dark noise in the cone is dominated by stimulusevoked noise from rods, and actual loss of sensitivity is $<1.5$-fold (Fig. 9). The reason is that, in dim light, the rod single-photon response exceeds that of the cone by $\sim 100$-fold (Schneeweis and Schnapf, 1999). In brighter light, stimulus-evoked $R^{*}$ in the cones grows much larger than the cone dark rate and at midphotopic intensity dark noise would decrease SNR by $<10 \%$, raising detection threshold from 1.83 to $2.0 \%$ contrast. Thus, in dim light, cone dark noise reduces contrast sensitivity but across most of the intensity range this loss is negligible compared with the measured fourfold loss.

A second possible cause of sensitivity loss is fluctuation of vesicle release. Calculations show that if the cone terminal releases vesicles with a mean rate of $\sim 750 \mathrm{~s}^{-1}$ (DeVries et al., 2006; Thoreson, 2007), then it follows from the known synaptic gain (Witkovsky et al., 2001) that detection threshold postsynaptic to a cone could be no better than $16 \%$ contrast (see Appendix), which agrees with the $18.0 \%$ contrast calculated from horizontal cell recordings. The release rate falls in bright light, which on first thought implies a loss of contrast sensitivity. However, a simple model showed that discriminability improved at low release rates, suggesting monotonic improvement of contrast sensitivity from dim to bright light (Choi et al., 2005). Thus, in the outer retina, vesicle fluctuation is probably the main cause of sensitivity loss, consistent with psychophysical results showing improvement of sensitivity with increasing background (Fig. 7B) (Banks et al., 1987).

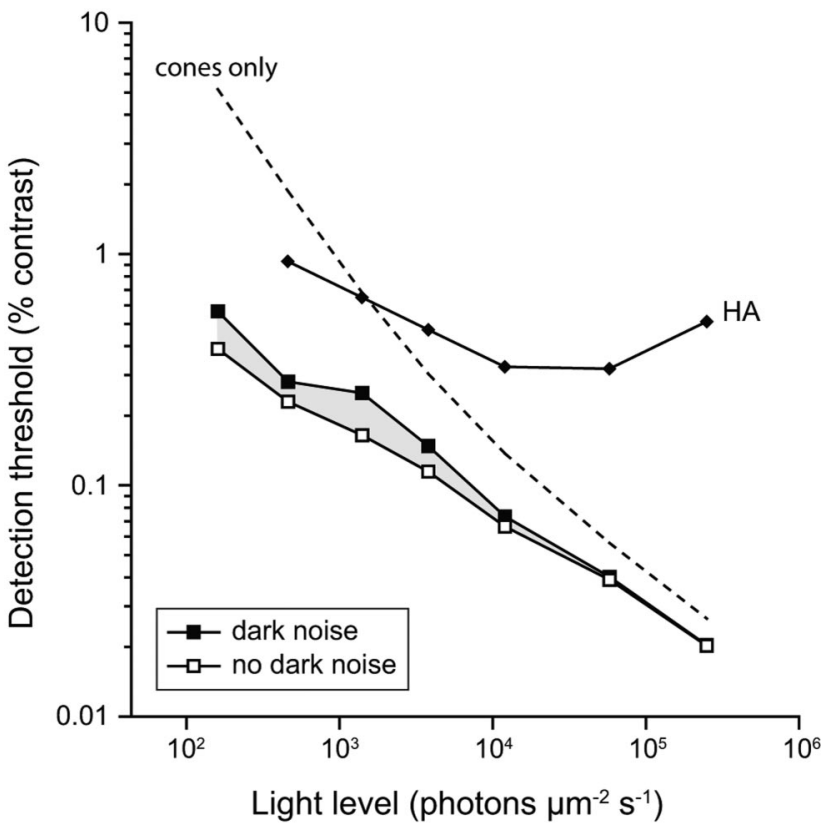

Figure 9. Cone dark noise accounts for $<25 \%$ of outer retinal information loss. Contrast detection threshold of the ideal model was approximately fourfold lower than detection threshold measured postsynaptic to the cones (HA). Attempting to explain the loss, we added cone dark noise to the cone signal. Because it is much smaller than rod photon noise, rod dark noise was omitted (see Materials and Methods). Taking the L-cone value as an upper bound to the dark rate. We found that, in dim light, it accounts for $<25 \%$ of the measured loss (shaded area). In brighter light $\left(>5 \times 10^{3}\right.$ photons $\left.\mu \mathrm{m}^{-2} \mathrm{~s}^{-1}\right)$, the effect of cone dark noise on the postsynaptic detection threshold is negligible. That dark noise in the cone causes little information loss is explained by the known rod-cone coupling (Yin et al., 2006). Without rod inputs, cone dark noise would cause a sharp rise of the detection threshold in dim light (dotted line). With rod coupling, the strong light-evoked photon signal transmitted from multiple neighboring rods sum in a single cone and exceed the dark noise by manyfold, even when light levels are low. The rod contribution to the cone is light dependent (Yin et al., 2006) and gradually declines, whereas the signal of the cone gains strength. This mechanism ensures that, from dim to bright light, dark noise in the cones does not increase threshold by more than $\sim 1.5$-fold.

At the second synaptic stage, the bipolar release rate is lower, which might increase loss. However, the bipolar cell response is larger and its timing is sharper (Freed et al., 2003; Sterling and Freed 2007) so that vesicle fluctuations may be relatively smaller. An additional loss occurs when the graded signal is converted to spikes, which inevitably adds noise and reduces sensitivity (van Rossum et al., 2003). Indeed, a twofold loss was observed between the graded potential of the ganglion cell and its spike output (Dhingra and Smith, 2004), suggesting that the 3.5-fold loss from bipolar to ganglion cell output combines comparable losses caused by vesicle fluctuation and spike generation.

\section{Comparing retinal loss to the overall loss}

The apparent factors causing the approximately 10-fold sensitivity loss from phototransduction to ganglion cell spike output reflect fundamental properties of mammalian retina (see above). Therefore, we expect that this fractional loss will be similar across mammalian retinas, including human. Naturally the absolute sensitivities of ganglion cells will differ depending on species-specific photoreceptor densities, cone convergence, etc. But when these speciesspecific values are accounted for in a preneural model (such as Fig. 1 ), because of the similar fundamental properties the fractional loss across the retina should be similar. If so, the overall sensitivity loss measured psychophysically by Banks and colleagues as 5- to 10-fold would be explained by losses within retina. 


\section{How many ganglion cells contribute to psychophysical detection?}

Watson et al. (1983) asked famously, "What does the eye see best?" What they actually asked experimentally was, "What stimulus does the ensemble visual system detect at lowest contrast? Their answer was a small, brief spot, whose size we now know approximately matches the receptive field of a foveal brisk-transient ganglion cell (Calkins and Sterling, 2007). Indeed, their psychophysical detection threshold approximates the detection threshold of a brisk-transient geniculate cell (Derrington and Lennie, 1984). This cell type collects from the most cones via the most synapses (Xu et al. 2008), and no other known cell type is more sensitive. Furthermore, as noted by Dhingra et al., a spot that just fills the receptive field center of a brisk-transient cell covers the surrounds of the adjacent smaller cells, further reducing their sensitivities. Thus, at contrast threshold for a brisk-transient cell, other types are unlikely to respond.

If the brisk-transient type is indeed responsible for behavioral detection, the question arises: how many cells of this type respond to spot onset at contrast threshold? This was specifically tested by recording in guinea pig from pairs of adjacent ON or OFF brisktransient cells (Borghuis et al., 2008). The answer is that when a spot at threshold contrast covers the center of one cell, only that cell fires; the adjacent cells do not respond. Furthermore, when the spot falls between two cells, sensitivity based on the spikes from both does not exceed that for a spot over one's center. Thus, we conclude that one brisk-transient cell, or the equivalent response from its immediate neighbors, account for all the spikes evoked by that stimulus leaving the retina. If the human brisktransient cell behaves similarly in this respect, one would conclude that its response is sufficient to explain psychophysical detection.

\section{Appendix}

We asked what is the sensitivity limit set by the cone synaptic vesicle release rate? Assuming Poisson release with rate $r$, the change in released number of synaptic vesicles required for significant detection $(68 \%$ correct) of a flash with duration $t$ is the following:

$$
\Delta S v=\sqrt{r \cdot t} .
$$

If sustained cone release at photopic background is $750 \mathrm{sv} / \mathrm{s}$, and stimulus duration is $100 \mathrm{~ms}$, then assuming Poisson release statistics, significant detection $(1 \mathrm{SD})$ requires $\sqrt{ } 75=8.7$ additional synaptic vesicles (i.e., a 0.12 -fold change in release).

At a membrane voltage of $-45 \mathrm{mV}$, a doubling of synaptic glutamate release requires a $5.3 \mathrm{mV}$ change in membrane potential (Witkovsky et al., 2001). Thus, using a linear fit to the glutamate release function, a 0.12 -fold change should require a $0.12 \times 5.3=$ $0.61 \mathrm{mV}$ change in membrane potential. Although the real transfer function is nonlinear, we assumed linearity as a first approximation. This is accurate for small deviations from the mean, which holds for the response to the low-contrast stimuli used here.

How much current is required to give the required change in membrane voltage $\Delta V(0.61 \mathrm{mV})$ depends on the cone membrane resistance. Dividing reported voltage responses by current responses measured for the same light flashes (Schneeweis and Schnapf, 1999), we computed a cone membrane resistance $R$ of $400 \mathrm{M} \Omega$. Thus, it follows that to evoke a $0.61 \mathrm{mV}$ change in membrane voltage requires a change in current $I$ with magnitude as follows:

$$
\Delta I=\Delta V / R=1.53 \mathrm{pA}
$$

Dunn et al. (2007) showed that against a background intensity of $1000 P^{*} / \mathrm{s}$, one $P^{*}$ evokes in a primate cone a current of $0.04 \mathrm{pA}$. Against a background of $10,000 P^{*} / \mathrm{s}$, the current response is smaller, $0.02 \mathrm{pA}$, because of the reduced response gain at higher light intensity. Interpolating their data, it follows that at our background intensity of $1.2 \times 10^{4}$ photons $\mu \mathrm{m}^{-2} \mathrm{~s}^{-1}$ (equivalent to 2700 $P^{*} \cdot$ cone $\left.{ }^{-1} \cdot \mathrm{s}^{-1}\right)$, one $P^{*}$ evokes a current of $0.035 \mathrm{pA}$. Therefore, the required $1.53 \mathrm{pA}$ current in the cone requires a minimum of $1.53 / 0.035=44 P^{*}$. For a $100 \mathrm{~ms}$ flash, $44 P^{*}$ is equivalent to an intensity increase of $440 P^{*} /$ s. Against a mean background evoking $2700 P^{\star}$ per second, this is $16.2 \%$ contrast. Thus, the release rate of a cone sets the lower bound for the detection threshold postsynaptic to a single cone at $16.2 \%$ contrast, just 1.25 -fold lower than the measured threshold (20.4\%) (see Results, Sensitivity loss across the first synapse). These calculations suggest that the fidelity of contrast signaling at the cone synapse is close to the bound set by quantal fluctuations in synaptic vesicle release.

\section{References}

Ala-Laurila P, Pahlberg J, Koskelainen A, Donner K (2004) On the relation between the photoactivation energy and the absorbance spectrum of visual pigments. Vision Res 44:2153-2158.

Banks MS, Geisler WS, Bennett PJ (1987) The physical limits of grating visibility. Vision Res 27:1915-1924.

Banks MS, Sekuler AB, Anderson SJ (1991) Peripheral spatial vision: limits imposed by optics, photoreceptors, and receptor pooling. J Opt Soc Am A 8:1775-1787.

Barlow HB (1962) Measurements of the quantum efficiency of discrimination in human scotopic vision. J Physiol 160:169-188.

Barlow HB (1972) Single units and sensation: a neuron doctrine for perceptual psychology? Perception 1:371-394.

Barlow HB, Levick WR, Yoon M (1971) Responses to single quanta of light in retinal ganglion cells of the cat. Vision Res Suppl 3:87-101.

Baylor DA, Nunn BJ, Schnapf JL (1984) The photocurrent, noise and spectral sensitivity of rods of the monkey Macaca fascicularis. J Physiol 357:575-607.

Berntson A, Smith RG, Taylor WR (2004) Transmission of single photon signals through a binary synapse in the mammalian retina. Vis Neurosci 21:693-702.

Blinkov SM, Glezer II (1968) The human brain in figures and tables. A quantitative handbook. New York: Plenum.

Borghuis BG, Ratliff CP, Smith RG, Sterling P, Balasubramanian V (2008) Design of a neuronal array. J Neurosci 28:3178-3189.

Burkhardt DA, Fahey PK, Sikora MA (2007) Retinal bipolar cells: temporal filtering of signals from cone photoreceptors. Vis Neurosci 24:765-774.

Calkins DJ, Sterling P (2007) Microcircuitry for two types of achromatic ganglion cell in primate fovea. J Neurosci 27:2646-2653.

Chichilnisky EJ (2001) A simple white noise analysis of neuronal light responses. Network 12:199-213.

Chichilnisky EJ, Kalmar RS (2002) Functional asymmetries in ON and OFF ganglion cells of primate retina. J Neurosci 22:2737-2747.

Chichilnisky EJ, Rieke F (2005) Detection sensitivity and temporal resolution of visual signals near absolute threshold in the salamander retina. J Neurosci 25:318-330.

Choi SY, Borghuis BG, Borghuis B, Rea R, Levitan ES, Sterling P, Kramer RH (2005) Encoding light intensity by the cone photoreceptor synapse. Neuron 48:555-562.

Cohen E, Sterling P (1990) Convergence and divergence of cones onto bipolar cells in the central area of cat retina. Philos Trans R Soc Lond B Biol Sci 330:323-328.

Crowell J, Banks MS, Anderson SJ, Geisler WS (1988) Physical limits of grating visibility: Fovea and periphery. Invest Ophthalmol Vis Sci Suppl 29:139.

Dacheux RF, Raviola E (1982) Horizontal cells in the retina of the rabbit. J Neurosci 2:1486-1493.

Dartnall HJ (1968) The photosensitivities of visual pigments in the presence of hydroxylamine. Vision Res 8:339-358.

Derrington AM, Lennie P (1984) Spatial and temporal contrast sensitivities of neurones in lateral geniculate nucleus of macaque. J Physiol 357:219-240. 
de Ruyter van Steveninck RR, Laughlin SB (1996) The rate of information transfer at a graded-potential synapse. Nature 379:642-645.

DeVries SH, Li W, Saszik S (2006) Parallel processing in two transmitter microenvironments at the cone photoreceptor synapse. Neuron 50:735-748.

Dhingra NK, Smith RG (2004) Spike generator limits efficiency of information transfer in a retinal ganglion cell. J Neurosci 24:2914-2922.

Dhingra NK, Kao YH, Sterling P, Smith RG (2003) Contrast threshold of a brisk-transient ganglion cell in vitro. J Neurophysiol 89:2360-2369.

Duda RO, Hart PE, Stork DG (2001) Pattern classification, Ed 2. New York: Wiley.

Dunn FA, Lankheet MJ, Rieke F (2007) Light adaptation in cone vision involves switching between receptor and post-receptor sites. Nature 449:603-606.

Freed MA (2000) Rate of quantal excitation to a retinal ganglion cell evoked by sensory input. J Neurophysiol 83:2956-2966.

Freed MA, Sterling P (1988) The ON-alpha ganglion cell of the cat retina and its presynaptic cell types. J Neurosci 8:2303-2320.

Freed MA, Smith RG, Sterling P (2003) Timing of quantal release from the retinal bipolar terminal is regulated by a feedback circuit. Neuron 38:89101.

Geisler WS (1989) Sequential ideal-observer analysis of visual discriminations. Psychol Rev 96:267-314.

Geisler WS, Albrecht DG, Salvi RJ, Saunders SS (1991) Discrimination performance of single neurons: rate and temporal-pattern information. J Neurophysiol 66:334-362.

Green DM, Swets JA (1966) Signal detection theory and psychophysics. New York: Wiley.

Haverkamp S, Grünert U, Wässle H (2001) The synaptic architecture of AMPA receptors at the cone pedicle of the primate retina. J Neurosci 21:2488-2500.

Hecht S, Shlaer S, Pirenne M (1942) Energy, quanta, and vision. J Gen Physiol 25:819-840.

Heidelberger R, Thoreson WB, Witkovsky P (2005) Synaptic transmission at retinal ribbon synapses. Prog Retin Eye Res 24:682-720.

Hemilä S, Lerber T, Donner K (1998) Noise-equivalent and signal-equivalent visual summation of quantal events in space and time. Vis Neurosci 15:731-742.

Hornstein EP, Verweij J, Li PH, Schnapf JL (2005) Gap-junctional coupling and absolute sensitivity of photoreceptors in macaque retina. J Neurosci 25:11201-11209.

Kiorpes L, Tang C, Hawken MJ, Movshon JA (2003) Ideal observer analysis of the development of spatial contrast sensitivity in macaque monkeys. J Vis 3:630-641.

Koch K, McLean J, Segev R, Freed MA, Berry MJ, 2nd, Balasubramanian V, Sterling P (2006) How much the eye tells the brain. Curr Biol 16:14281434.

Knowles A (1982) The biochemical aspects of vision. In: The senses (Barlow HB, Mollon JD, eds), pp 82-101. Cambridge, UK: Cambridge UP.

Laughlin SB, de Ruyter van Steveninck RR, Anderson JC (1998) The metabolic cost of neural information. Nat Neurosci 1:36-41.

Manookin MB, Beaudoin DL, Ernst ZR, Flagel LJ, Demb JB (2008) Disinhibition combines with excitation to extend the operating range of the OFF visual pathway in daylight. J Neurosci 28:4136-4150.

Mastronarde DN (1983) Correlated firing of cat retinal ganglion cells. II. Responses ofX-and Y-cells to single quantal events. J Neurophysiol 49:325-349.

Nakatani K, Tamura T, Yau KW (1991) Light adaptation in retinal rods of the rabbit and two other nonprimate mammals. J Gen Physiol 97:413-435.

Nelson R (1977) Cat cones have rod input: a comparison of the response properties of cones and horizontal cell bodies in the retina of the cat. J Comp Neurol 172:109-135.

Packer OS, Dacey DM (2002) Receptive field structure of H1 horizontal cells in macaque monkey retina. J Vis 2:272-292.

Peichl L, González-Soriano J (1994) Morphological types of horizontal cell in rodent retinae: a comparison of rat, mouse, gerbil, and guinea pig. Vis Neurosci 11:501-517.
Raviola E, Gilula NB (1975) Intramembrane organization of specialized contacts in the outer plexiform layer of the retina. A freeze-fracture study in monkeys and rabbits. J Cell Biol 65:192-222.

Rieke F, Baylor DA (2000) Origin and functional impact of dark noise in retinal cones. Neuron 26:181-186.

Röhlich P, van Veen T, Szél A (1994) Two different visual pigments in one retinal cone cell. Neuron 13:1159-1166.

Sarpeshkar R (1998) Analog versus digital: extrapolating from electronics to neurobiology. Neural Comput 10:1601-1638.

Savage GL, Banks MS (1992) Scotopic visual efficiency: constraints by optics, receptor properties, and rod pooling. Vision Res 32:645-656.

Schneeweis DM, Schnapf JL (1995) Photovoltage of rods and cones in the macaque retina. Science 268:1053-1056.

Schneeweis DM, Schnapf JL (1999) The photovoltage of macaque cone photoreceptors: adaptation, noise, and kinetics. J Neurosci 19:1203-1216.

Sekiguchi N, Williams DR, Brainard DH (1993) Efficiency in detection of isoluminant and isochromatic interference fringes. J Opt Soc Am A Opt Image Sci Vis 10:2118-2133.

Smith RG, Freed MA, Sterling P (1986) Microcircuitry of the dark-adapted cat retina: functional architecture of the rod-cone network. J Neurosci 6:3505-3517.

Snyder AW, Pask C (1973) The Stiles-Crawford effect-explanation and consequences. Vision Res 13:1115-1137.

Sterling P, Freed M (2007) How robust is a neural circuit? Vis Neurosci 24:563-571.

Sterling P, Matthews G (2005) Structure and function of ribbon synapses. Trends Neurosci 28:20-29.

Stiles WS, Crawford BH (1933) The luminous efficiency of rays entering the eye pupils at different points. Proc R Soc B 112:428-450.

Tamura T, Nakatani K, Yau KW (1989) Light adaptation in cat retinal rods. Science 245:755-758.

Taylor WR, Smith RG (2004) Transmission of single-photon signals from the rod to rod-bipolar cell in the mammalian retina. Vision Res 44:3269-3276.

Thoreson WB (2007) Kinetics of synaptic transmission at ribbon synapses of rods and cones. Mol Neurobiol 36:205-223.

van Rossum MC, O’Brien BJ, Smith RG (2003) Effects of noise on the spike timing precision of retinal ganglion cells. J Neurophysiol 89:2406-2419.

Wässle H, Boycott BB, Peichl L (1978a) Receptor contacts of horizontal cells in the retina of the domestic cat. Proc R Soc Lond B Biol Sci 203:247-267.

Wässle H, Peichl L, Boycott BB (1978b) Topography of horizontal cells in the retina of the domestic cat. Proc R Soc Lond B Biol Sci 203:269-291.

Wässle H, Puller C, Müller F, Haverkamp S (2009) Cone contacts, mosaics, and territories of bipolar cells in the mouse retina. J Neurosci 29:106-117.

Watson AB, Barlow HB, Robson JG (1983) What does the eye see best? Nature 302:419-422.

Westheimer G (1967) Dependence of the magnitude of the Stiles-Crawford effect on retinal location. J Physiol 192:309-315.

Witkovsky P, Thoreson W, Tranchina D (2001) Transmission at the photoreceptor synapse. Prog Brain Res 131:145-159.

Wu SM, Yang XL (1988) Electrical coupling between rods and cones in the tiger salamander retina. Proc Natl Acad Sci U S A 85:275-278.

Xu Y, Dhingra NK, Smith RG, Sterling P (2005) Sluggish and brisk ganglion cells detect contrast with similar sensitivity. J Neurophysiol 93:2388-2395.

Xu Y, Vasudeva V, Vardi N, Sterling P, Freed MA (2008) Different types of ganglion cell share a synaptic pattern. J Comp Neurol 507:1871-1878.

Yin L, Smith RG, Sterling P, Brainard DH (2006) Chromatic properties of horizontal and ganglion cell responses follow a dual gradient in cone opsin expression. J Neurosci 26:12351-12361.

Zaghloul KA, Manookin MB, Borghuis BG, Boahen K, Demb JB (2007) Functional circuitry for peripheral suppression in mammalian Y-type retinal ganglion cells. J Neurophysiol 97:4327-4340. 